Portland State University

PDXScholar

Fall 11-27-2013

\title{
Science Journals in the Garden: Developing the Skill of Observation in Elementary Age Students
}

Karinsa Michelle Kelly

Portland State University

Follow this and additional works at: https://pdxscholar.library.pdx.edu/open_access_etds

Part of the Educational Methods Commons, and the Elementary Education and Teaching Commons Let us know how access to this document benefits you.

Recommended Citation

Kelly, Karinsa Michelle, "Science Journals in the Garden: Developing the Skill of Observation in Elementary Age Students" (2013). Dissertations and Theses. Paper 1536.

https://doi.org/10.15760/etd.1536

This Thesis is brought to you for free and open access. It has been accepted for inclusion in Dissertations and Theses by an authorized administrator of PDXScholar. Please contact us if we can make this document more accessible: pdxscholar@pdx.edu. 
Science Journals in the Garden:

Developing the Skill of Observation in Elementary Age Students

by

Karinsa Michelle Kelly

A thesis submitted in partial fulfillment of the requirements for the degree of

Master of Science in Teaching

in

General Science

Thesis Committee:

Michael Flower, Chair

Stephanie Wagner

Olivia Murray

Portland State University

2013 


\begin{abstract}
The ability to make and record scientific observations is critical in order for students to engage in successful inquiry, and provides a sturdy foundation for children to develop higher order cognitive processes. Nevertheless, observation is taken for granted in the elementary classroom. This study explores how linking school garden experience with the use of science journals can support this skill. Students participated in a monthlong unit in which they practiced their observation skills in the garden and recorded those observations in a science journal. Students' observational skills were assessed using preand post-assessments, student journals, and student interviews using three criteria: Accuracy, Detail, and Quantitative Data. Statistically significant improvements were found in the categories of Detail and Quantitative Data. Scores did improve in the category of Accuracy, but it was not found to be a statistically significant improvement.
\end{abstract}


Table of Contents

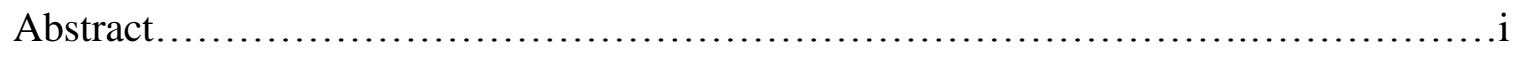

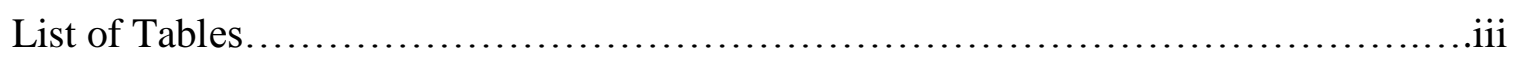

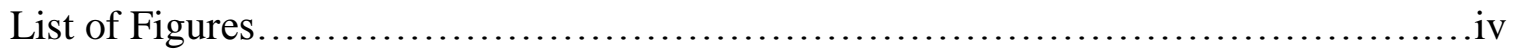

Introduction..............................................................

Review of Literature..........................................................

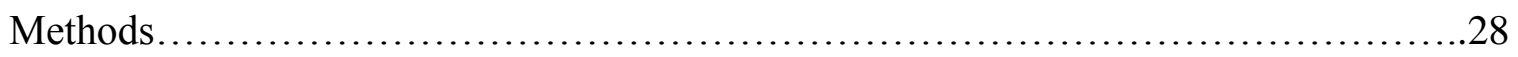

Results............................................................... 39

Discussion................................................................ 51

References...........................................................59

Appendices

A. Unit Outline.....................................................61

B. Assessment Rubric.................................................63

C. Interview Questions............................................64 


\section{List of Tables}

1. Examples of student responses to the question, "What makes a good scientific observation?" ........................................................ 48 


\section{List of Figures}

1. Racial/Ethnic Background, Summerland School, 2012 .............................. 30

2. Average Performance on Pre- and Post-Assessments............................................

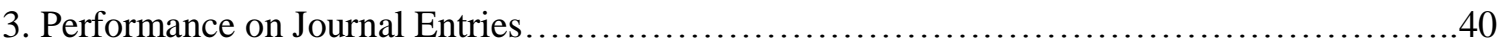

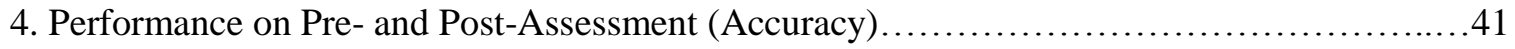

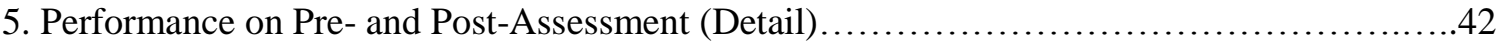

6. Performance on Pre- and Post-Assessment (Quantitative Data)...........................49 


\section{Introduction}

The American educational system is currently experiencing a shift in how science is taught to students. Although the reality is that many teachers remain dependent on rote memorization of facts and the dispersion of content knowledge with no context, a push is coming from educators and policy makers to make science instruction more engaging. This means teaching students about the "big ideas" in science, encouraging critical thinking rather than memorization, and giving students an opportunity to do science as scientists would (National Research Council, 2011). In order to effectively act as scientists, students need to develop certain skills and practices. As the upcoming nationally developed Next Generation Science Standards are adopted at the state level, students will be expected to demonstrate these skills and practices in the classroom.

The skill of observation is often considered to be the very foundation of the hierarchy of those science skills. The ability to make scientific observations affects students' ability to formulate testable questions, to record accurate and relevant data in an inquiry, and to make inferences based on the outcomes of experiments (Eberbach \& Crowley, 2009). Without solid observations, a science inquiry experience in an educational setting is significantly less valuable. Nonetheless, many students make it through elementary school without knowing what makes an observation scientific, and without the opportunity to practice this critical skill. Too often, observation is perceived as an easy skill that students should have mastered early on, and when it is practiced it is removed from all context and reduced in complexity (Ford, 2005).

Often children are reluctant to make detailed records of their observations, even when they are enthusiastic about the observational process (Ford, 2005). When they do 
make records, they are frequently incomplete (Garcia-Mila \& Anderson, 2007), irrelevant (Schauble, 1990), or inaccurate (Kuhn, 1995). Multiple studies show that when observation is not couched in authentic, discipline-specific experiences, students' observations are markedly inferior (Eberbach \& Crowley, 2009; Ford, 2005). When students record their observations in a science journal, they feel as though they are doing science as a scientist does, thus placing their experience in the authentic context they need. Drawing on experiential learning theory, McQuitty (2009) argues that when students use science journals, "The ideas generated are inherently meaningful because students constructed them through hands-on experience" (p. 29). Finally, the act of writing in a science journal is considered a form of knowledge transforming, which research has shown can have a positive effect on student understanding of science concepts (Gunel, Hand \& Prain, 2007).

Science journals are currently receiving a great deal of attention in the educational community, yet the exact definition of a science journal remains nebulous. The term "science journal" is often used interchangeably with "science notebook", with the term "field journal" or "field notebook" also occurring in the literature. Research, as well as teacher support material, varies in definitions and uses of science journals. At one end of the continuum is a very student-led approach wherein students are encouraged to use journals as they want, with no prompts or requirements for inclusion, and often with no teacher assessment. At the other end is a strict teacher-dominated approach, in which each page of the journal has a specific purpose, the elements of each entry are clearly defined, and teachers give grades based on content and literacy. Research has yet to determine if one approach is more effective than the other. For the purposes of this study, 
the science journals will fall somewhere in the middle of the spectrum, with some prompts and expectations for included information, but with plenty of room for student creativity. The journals will be assessed as part of the research data set, but will not be used for academic assessment, except in a formative manner.

A school garden is an ideal setting in which to use these science journals to practice recording observations. Experiential learning theory also informs the literature surrounding school gardens, which finds that direct experience with the magic of the natural world attracts and holds students' attention (Kellert, 2002). The garden is everchanging and full of natural phenomena that elicit wonder in a child, leading to increased motivation to participate. This motivation may be a key factor in improving science skills (Mabie \& Baker, 1996). The garden also provides a discipline-specific context in which children can observe, which researchers have argued repeatedly is critical (Eberbach \& Crowley, 2009; Ford, 2005). The unique combination of factors that coalesce when science journals are used in a school garden should have a powerful effect on students' observation skills, particularly when students are given explicit instrNe uction and opportunities to practice.

This study addresses the question, "Does the use of science journals in a school garden setting improve students' observation skills?" In the context of this study, observational skills were assessed according to criteria determined by looking at two main sources (Accuracy, Detail, and the Inclusion of Quantitative Data.) First, Eberbach and Crowley (2009) investigate how expert scientists observe and record and use those observations in the real world, which informs the ultimate goals for student observations. Secondly, those researchers and others evaluate what student observations actually look 
like (Ford, 2005; Shepardson, 2001; Johnston, 2009). The goal of the study is to determine participants' baseline observational skills, and then implement a treatment that will improve those skills in terms of the above criteria.

This treatment was student participation in a month-long unit on plants, during which they received explicit instruction on making and recording high quality scientific observations, and they were given the opportunity to practice those skills using a science journal in a school garden. I expected to see significant improvement in the students' observations. "Improvement" was evaluated using pre- and post-assessments, student journals, and interviews.

Following the treatment, I anticipated that students' observations would be much more rich and descriptive than in their pre-tests. Also, elementary age students typically rely heavily on qualitative data and neglect to record quantitative data (Eberbach \& Crowley, 2009). Following explicit instruction and opportunities to practice, I expect students to include many more specific measures of quantitative data in their observations. This foundation of more robust observation skills should have myriad positive effects for the students in their future lives, from improving their ability to conduct a successful inquiry project in the classroom to providing a strong basis for developing higher order thinking skills, more advanced science process practices, and a deeper understanding of both science concepts and content. 


\section{$\underline{\text { Review of Literature }}$}

The following literature review addresses three major research areas pertinent to my study. The first section examines school gardens, particularly benefits to student participants. A review of literature surrounding science journals follows, including their overlapping uses in science and literacy, as well as challenges in assessing student work. Finally, I address children's observation skills: how they develop, what they look like, and how they can be supported.

\section{Benefits of school gardening}

The body of research literature regarding school gardens is vast and addresses a wide range of relevant subjects. Blair (2009) conducted a literature review of the topic with the intention of answering the question, “... whether a school garden, without causing extensive changes to the schoolyard or integrating broader environmental fieldwork into the curriculum, provides sufficient experiential education to cause measurable and observable changes in student achievement and behavior" (p. 16). Although the author critiques many of the studies reviewed, finding common methodological issues, she does conclude that the results are consistent enough throughout the research to claim that benefits exist. Before she reaches this conclusion she systematically evaluates the body of literature to find common themes and conclusions.

Blair begins the review by giving a broad overview of the history and current status and scope of the school garden movement, and then moves toward addressing the various ways in which school gardens are typically justified. Some of the most 
noteworthy rationales for gardening involve the development of higher order cognitive skills. The stimulation of the outside environment and the experiential aspect that often accompanies outside education both support the types of cognition associated with the upper levels of Bloom's taxonomy. Blair posits these types of critical thinking skills are under-supported in typical classroom curricula, and that experiential education can be especially effective in supporting them. In particular, the unstructured and spontaneous learning opportunities that accompany involvement in a long-term project such as maintaining a vegetable garden allow students to make discoveries on their own terms and to take ownership of them.

Following her list of rationales, Blair goes on to discuss in more detail some of the most pertinent studies on the subject, as well as to address some of the commonalities across the literature. The types of learning outcomes were one of the most studied aspects, concluding that the most common learning outcome to be studied was health and nutrition. Other frequent topics were environmental education, self-esteem or selfconcept, academic achievement (particularly in science), and life or social skills.

Blair then focuses on school garden research that has used quantitative data. She identifies twelve studies, the majority of which studied students in third through sixth grades. These studies vary in research topic, but find improvements in science scores, nutritional preferences, and environmental attitudes. Less significant difference is noted in nutritional knowledge, and results are inconclusive in studies that look at impacts on environmental behaviors. Although these twelve studies are quantitative in nature, Blair warns that there may be validity issues associated with their designs. Lack of randomization, uncontrolled differences in teacher training and enthusiasm, classroom 
effects and potential ethnicity issues are cause for concern when evaluating the results of these studies.

Next Blair looks at results from seven qualitative research studies, pulling out eight common themes. All of the cited research found excitement and delight in their participants regarding the garden, improvements in school involvement and pride, an increase in feelings of community, and multiple opportunities for learning and environmental stewardship. Four of the studies reported opportunities for students to engage with the natural environment. Four studies also found that the key to successful school gardens was the presence of at least one adult who was educated and enthusiastic about gardening. On a related note, two studies found a general lack of knowledge about plants or skills in growing them by the involved teachers. The author's primary critique of these qualitative studies is that many of them were designed or implemented by the researchers themselves, thus introducing potential researcher bias. She notes, however, that the researchers' involvement does lead to a greater ability to evaluate the relationship between the garden and the child.

In conclusion, Blair would like to report a positive answer to her research question, but finds that her concern over methodological issues prevents her from reporting a conclusive yes. She offers several solutions for increasing validity and rigor in future research, including the possibility of combining qualitative and quantitative data in the same study. She also presents several suggestions for future research topics, including the effects of school principals on garden projects, how best to encourage garden success, and how long these purported benefits persist. 
Of particular interest in Blair's study are Klemmer, Walicek and Zajicek (2005), who find a significant difference in science achievement between students who participated in a school garden program and those who did not. Science achievement was measured by a cognitive test instrument administered to all participants at the end of the study. The instrument was developed by teachers, curriculum specialists and the researchers. The study took place over the course of a school year with 647 third-, fourthand fifth-graders, during which all participating classes followed the same ageappropriate curriculum guidelines. Teachers in the experimental group incorporated as much hands-on garden experience as possible, while teachers in the control group incorporated none. Results of the study show a statistically significant increase in test scores for the students who participated in the garden component. The majority of that increase was attributed to a difference in scores by the fifth-graders, which the researchers speculate may be due to the older students' increased ability to synthesize their experience in the garden with information from the classroom.

In contrast, a study by Pigg, Waliczek and Zajicek in 2006 found no statistical difference in the science scores of third-, fourth- and fifth-graders who participated in a school garden program versus those who did not. Teachers in this study used a particular garden curriculum that was designed to address several disciplines, including science, and were encouraged to utilize the curriculum as much as possible. Science achievement was measured at the end of the spring semester by the same test as in the Klemmer et al. study. Pigg et al. did not find statistically significant differences in the students' science scores, but they did find a difference in math scores, despite the fact that math was not one of the subject areas addressed in the curriculum. 
Science is often an important part of curricula associated with school gardens, and increases in science achievements are commonly touted as a rationale for using school gardens. However, Blair's (2009) review of the literature actually reveals a dearth of solid research to support this. The research that does exist focuses solely on the effect on science content knowledge, while the current push in education reform has begun to emphasize scientific skills and practices as much or more than content knowledge. Although the movement in support of school gardens is strong, more research clearly needs to be done to explore what the benefits actually are as they relate to children's understandings of science.

Uses, effects and assessments of science journals

A considerable body of work exists concerning the uses of journaling in elementary classrooms, both as a strategy for increasing science understanding and as a literacy strategy. The majority of the literature comes from one discipline or the other, but McQuitty, Dotger and Khan (2009) attempt to merge the two. They find that although the research coming out of the science education community implies that combining science and writing can support learning in both areas, research coming from the literacy community is less convincing.

The authors argue that there are actually several similarities in the processes of science and writing, equating the recursive nature of writing and revising with the process of replicating experiments. They describe the goal of their paper as "to build on these commonalities to develop a framework for integrated writing/science instruction" (McQuitty, Dotger \& Khan, 2009, p. 4). They begin their discussion of the subject with a 
look at germane theory and literature, then continue on to develop a framework for teaching the two subjects in an interdisciplinary fashion.

The researchers begin their literature review from the perspective of literacy education and concentrate on two techniques in particular: process writing instruction and the teaching of genre. They lay out the important facets of process writing instruction, such as drafting, revising, and engaging in inquiry, and cite several papers to describe and support these ideas. Particularly applicable is their discussion of journals in this process, where students can record thoughts and observations and then use their journals as jumping off points for the writing process. Although the researchers believe that science writing could be taught from a process writing perspective, they find little in the literature to support that idea. Most work that combines the two disciplines falls under the umbrella of genre theory.

Genre theory stresses the social and cultural aspects of writing, in that genre writing is situated specifically within a particular discipline and has forms and purposes that are unique to that discipline. Although genre theory is well defined, teaching strategies for this type of writing are less straightforward, and there is some contention between theorists from the two perspectives. Genre theorists believe in explicitly teaching writing skills within the genre, but research has thus far not shown this to be an effective strategy for improving science writing.

From a science education perspective, writing is usually considered using writingto-learn techniques. The researchers are particularly interested in two specific models, knowledge telling and knowledge transforming. One example of a knowledge transforming strategy is the usage of science journals, although some would argue that 
journals belong more in the knowledge telling category. Knowledge transforming tasks are considered to be more supportive of student learning, so the goal in using journals would be to use them in a manner consistent with that technique. The authors cite research that finds that student learning through journals can be very dependent on teacher influence. Amounts of guidance from the teacher, the type of experience during which the students are writing, and the type of writing they are encouraged to produce all have effects on the outcome. However, McQuitty et al. believe more research is needed to determine how teachers can best use journals in the classroom. They also explore the science/writing connection through the lens of writing-to-communicate strategies, and they find that these methods can also be effective.

The researchers lay out their own framework for interdisciplinary science/writing instruction, which attempts to advance previous work done on integrating multiple perspectives. McQuitty et al. incorporate two main techniques into their framework, writing for authentic audiences and using science journals. They argue that science journals are a tool for learning science as opposed to communicating science, and therefore students should be allowed to use everyday language and determine their own methods for recording. Furthermore, they determine that formally assessing science journals may be counterproductive (especially if writing techniques are targeted), as assessment may inhibit students' creativity and motivation. They also caution against expecting students to record only pertinent information, as they see journals as a place to record any information that seems important at the time with the intention of making more sense later. 
The authors point to Klentschy's 2005 work that suggests specific components for inclusion in science journals that are informed by the inquiry process and constructing scientific explanations. Using this as a guideline, they argue that for the richest learning to occur teachers need to be explicit in their instructions, citing research by Baxter et al. (2001) and Shepardson and Britsch (2000) that found that science learning and reasoning improvements are not guaranteed following science journal usage. The researchers develop their framework based on Klentschy's components as well as interactive writing methods developed by other researchers. They advocate for modeling journal use in a whole-class setting and then increasing students' independent usage, while simultaneously encouraging growth toward sophistication in writing.

The researchers turn next from using a science perspective to a literacy perspective with the argument that journals can be used as a prewriting tool. They claim that journal usage can help students develop meaningful topics. The next step in their framework is using information recorded in the students' journals to communicate for authentic audiences. Finally, McQuitty et al. lay out ideas for future research, including which structures of science journals may be most effective for promoting learning.

As part of a larger and longer study on the effects of science journal usage on student performance and teacher practices, Aschbacher and Alonzo (2006) address three specific effects:

“1) How well did journal scores predict other measures of students’ conceptual understanding?

2) How did teachers' patterns of journal use affect the inferences teachers might draw from them - that is, their utility as a formative assessment tool? 
3) What factors inhibited teachers' use of journals to assess students' conceptual understanding?" (p. 182)

Although Aschbacher and Alonzo use a fairly loose definition of science journal ("a set of student writings and drawings that describe and reflect inquiry experiences as they occur within the science classroom" [p. 182]), the teacher participants were encouraged to use a somewhat more restricted framework for the journals that corresponded closely to an inquiry process. The journals ideally included some specific components, including a research question, data records, and evidence to support claims, but were also open to other inclusions such as predictions and future research questions, and some experimentation was encouraged.

The researchers used both qualitative and quantitative data from the journals, as well as pre- and post-tests, interviews, and a performance assessment. Student participants were 4th and 5th graders primarily from low-income families, and many students were English language learners. The participants were from four districts and the study included teachers with a wide variety of teaching experience, science content knowledge, and training in integrating science journals into curriculum.

Science journals were evaluated using scoring rubrics designed by the researcher to assess student understanding of the concepts being taught during the unit. Students were also assessed on the basis of a multiple-choice test administered as a pre- and posttest. The test addressed many of the same concepts from the unit as were expected in the science journals. A performance assessment designed to assess different concepts than the other two evaluations was administered mid-way through the unit. 
Aschbacher and Alonzo found that the performance on science journals did predict performance on the post-test to some extent, but that the effect was strongly influenced by how much training teachers had received in science journal instruction. Scores were more predictive for students in classes where teachers had received more training. The researchers propose several ideas as to why the journal scores were not consistent predictors of test performance. Journals and post-tests measure understanding at different points of the learning process, and they measure different types of abilities. Overall, they found that the value of using journals as a formative assessment tool might depend on the individual teacher.

Value of the journals as an assessment tool also depended heavily on the amount of guidance students received in what information to include. The researchers define four types of guidance, from minimal up to overly prescriptive, and find that students learn best when they are given a moderate amount of guidance. Moderate guidance would include some prompts as to what to write, but also freedom to put their learning in their own language rather than copying the "right" answer from the board.

Regarding the researchers' final question, the teachers' most common concern in utilizing the science journals was time. However, the researchers feel that time is merely a proxy for the real problem, which is a lack of training and content knowledge on the part of the teachers. This was a final problem with the use of science journals as an assessment tool, as many of the teachers were so unfamiliar with the concepts they were teaching that they were not able to competently assess student understanding beyond rote memorization of fact and vocabulary. 
Ashbacher and Alonzo's results are echoed in a report by Ruiz-Primo, Li and Shavelson (2002), where the researchers also find that efficacy of journal usage depended largely on the teacher in ten fifth-grade classrooms. They find that journals can be a valuable assessment tool, but they address several factors that can mitigate the journals' value. In general, they find that science journals reflect the instructional practice of the classroom and all the problems that may be inherent in that, from a lack of teacher understanding of content knowledge to too few opportunities to practice higher order cognitive skills. Additionally, they find that no teachers in their study used journals as a literacy strategy, providing feedback on spelling and grammar mistakes at best and zero feedback on communication quality at worst. Overall, they find that teacher feedback on journal entries was of poor quality, with the majority being a simple checkmark or grade with no in-depth comments to help students advance in their learning. The researchers' conclusion is that science journals can be a powerful tool in the classroom, but that teachers need to be much more intentional in their implementation if journals are to be used successfully.

Brenneman and Louro (2008) focus specifically on the use of science journals with young children, a population which poses some challenges with practicality of implementation and assessment. Their primary goal in journal usage is to support the recording of observations, which at this young age often entails using drawings rather than written language. The use of mainly visual representations means that it is often necessary to spend extra time or to employ creative methods to truly understand what the students have observed and recorded. The researchers posit that asking probing questions of the students not only enhances the researchers' understanding of their journal entries, 
but also actually models for the students the types of questions that they may eventually ask themselves while journaling.

A key objective of the authors' interactions with students is to reinforce the need to record what they actually observe, rather than what they have imagined. Although the teachers try to focus the children (often with verbal prompts), they do so using indirect language, and the students also have some degree of freedom. The researchers always model observing and recording before students are expected to do so in their journals. They argue that journaling supports children's observational skills because it provides them with motivation to carefully record their actual observations, rather than what they know to be true.

The researchers often encounter this type of misrepresentation of observations, and they find that it is well documented in the pertinent literature. They have had success with mediating this effect by providing certain constraints to the children, in particular asking that the children make two contrasting drawings. This encourages the child to focus on the relevant features. They also find that children's recordings are more representational when they are placed in a communicative context.

Brenneman and Lauro next switch their focus from how journaling supports science skills to how it can support language and literacy skills. They find that students using journals progress in their use of both descriptive language and complex sentence structure, and that journaling can be helpful for children who are still learning to sound out letters and words.

Finally, the researchers propose that journals can be a very effective assessment tool for young children. In particular, many of the literacy standards that are critical to 
address at this early age can be assessed in journals. Additionally, journals can provide a tangible record of student progression over time, and can provide teachers with an opportunity to gain insight into children's thinking processes.

Shepardson and Britsch (2001) concur with Brenneman and Louro's findings that children often record information in their journals that is not based on immediate reality. These researchers find that observations in journals tend to fall within one of three broad categories: imaginary, experienced, and investigative. They argue, however, that even when childrens' journal entries are not entirely accurate, they may still provide valuable insight into the child's thought process. Additionally, the process of creating the journal can provide students with an opportunity to present their experience through their own lens, thus helping the student make sense of the experience. The researchers' primary research concern is how children contextualize their science experience on the page, which they claim is a function of the child's familiarity with the phenomena, an idea echoed later in this literature review in the work of Eberbach and Crowley (2009). Recordings based on phenomena with which a child has experience are richer and exhibit higher order cognition.

Shepardson and Britsch looked at science journal use in one kindergarten and one fourth-grade classroom over the course of one academic year. They collected data based on journal entries and coded it for one of three "worlds": the imaginary, the experienced, and the investigative. Imaginary refers to recordings based on settings, characters or events that are created by the child, although actual observations are sometimes incorporated. Experienced reflects an actual previous experience the child has had in the real world, again often integrated with the experience of the class activity. Finally, 
investigative addresses the genuine current experience of the child during the journaling activity. All three of these categories are ways for a child to make sense of a science experience through a personal lens. The researchers find that kindergarteners are more likely to use the imaginary category in their recording, but that they are capable of progressing beyond this stage, and that advancing can be advantageous. The fourthgraders, on the other hand, were most likely to operate within the investigative category, producing records that have been echoed in other papers: step-by-step accounts of the process with little room for higher order skills like applying or inferring.

Finally, Shepardson and Britsch address the inherent difficulty in assessing journals in which the recordings may be inaccurate due to the way the child has contextualized the experience. They argue that journals are a crucial tool for determining how these three worlds inform childrens' understanding of an experience, and that journal assessment provides an opportunity for a teacher to assist a child in advancing to a new, more sophisticated lens. Overall, Shepardson and Britsch again echo other research: success in both implementation and assessment of journals in the classroom depends largely on the teacher.

As in the case of school gardens, the use of journals in science classrooms is currently receiving a lot of attention in the educational community. A review of the literature leads to a similar conclusion as above: while the use of journals clearly provides some benefit to children who use them (both in terms of science understanding and in development of literacy skills), additional research is necessary. Interesting and useful research could be done to fully determine what these benefits are, what the best uses of 
journals are, how journals can be implemented successfully in a classroom, and finally, how teachers can go about assessing their student work.

\section{Children's development of observation skills}

Eberbach and Crowley (2009) conduct a review of some of the literature surrounding the development of children's observation skills. They also create a framework that juxtaposes characteristics of children's typical "everyday" observations with those of expert scientists, along with a middle category that they consider to be transitional. Although they hypothesize that children may simply be unable to develop observation skills that they would consider "scientific," they do feel that with support and practice children may reach a transitional phase.

Eberbach and Crowley's research was inspired by a program in which middle school students' bird observations were found to have no effect on understanding of the associated content or of inquiry skills. To determine why this might be the case the researchers first looked at the literature surrounding observations by professional scientists, then looked at the literature surrounding children's emergent observation skills, and finally compared and contrasted the two.

The researchers begin with three primary points about observation skills in general: that observation is often underestimated and therefore under-supported, that observations can only be truly scientific in nature when they are conducted within a specific discipline, and that children need support in order to learn how to observe scientifically. 
Eberbach and Crowley focus their evaluation of adult scientific observation on biologists, and look especially closely at the ways in which scientists use observations and comparisons of morphological features to place organisms in a taxonomic system. The researchers look at several aspects of scientific observations: expert notice and reasoning, question asking, methods of documentation, and what they call "productive dispositions", a term used to describe the tendency of scientists to have a life-long enthusiasm for their subjects and a habit of observing them constantly.

The authors couch their investigation of children's observations in much the same terms as adult observations, with some slight differences. Notice and reasoning, documentation, and productive dispositions are still major foci, but they also address children's expectations and how those influence their observations. According to the literature, children tend to notice certain types of phenomena, particularly individuals or portions rather than populations or wholes. This tendency is affected by the amount of knowledge children have about their subject; as children learn more, their observations increase in depth and they are more able to make inferences from observed characteristics. The researchers argue, therefore, that observation that is not intertwined with disciplinary knowledge has somewhat limited value.

Eberbach and Crowley explore the ways in which children's expectations and observations can inform each other, finding that each can influence the other. Children obviously form expectations based on everyday observations, but they also tend to notice features and phenomena that support what they expected to encounter, even when evidence is available that contradicts their expectation. These preconceptions, along with 
the inherent complexity of the environment, impede children's ability to objectively analyze their observations.

The authors' exploration of the literature reveals that even the most enthusiastic observers are unlikely to make detailed records in childhood. When children do record their observations, the records are often incomplete or irrelevant, and usually go unused in the future. The researchers again attribute this in part to a lack of disciplinary knowledge, but also acknowledge that age may be a factor in a child's ability to make meaningful records.

Finally, Eberbach and Crowley address how children can be encouraged to make more scientific observations. Using the aspects of observation they addressed in the section on children's observations, they construct a framework that suggests what noticing, expectations, observational records and productive dispositions might look like in the cases of novice, intermediate and expert student observers. They then cite research that suggests ways of supporting the transition to novice to intermediate.

Johnston (2009) studies the observational process of fifty-six children from four to eleven years old and finds that the children's observations tended to fall into four distinct categories: affective, functional, social, and exploratory. Although all ages exhibited all types of observations, the author determines that observations increased both in quantity and sophistication with the age of the child. Affective comments show interest in a toy. Functional comments describe a toy. Social questions or comments are made as part of an interaction. Exploratory comments are questions, as in determining how a toy worked. 
Children were videotaped playing with novel small toys, and were also interviewed by the researcher following their play session. The toys fell into six groupings based on the mechanism that triggered movement, i.e. magnetic, electric, or spinning. Children had five minutes of uninterrupted independent play with the toys then spent five minutes explaining the toy to the researcher, with both open- and closed-ended questions posed by the researcher. Finally, the children were asked to sort the toys into groups of their own choosing.

Johnston looks at the numbers and types of observations made by the children during the introductory activity, the effects of different types of social interactions on their observations, and how the children's observations led to demonstrations of other higher order science process skills. During the initial independent play, observations were similar across ages, with only minor differences in quantity and sophistication. Differences were more pronounced during the second activity, in which the children explained the toys to the researchers. Younger children tended to make more descriptive observations, while older children were more likely to interpret in detail how the toys worked. Younger children produced more numerous hypotheses but these hypotheses were less sophisticated. In the sorting activity, the difference in ages was quite pronounced as younger children tended to categorize into groups like color, while older children focused more on function, i.e. spinning or jumping toys. The oldest children categorized according to the toy's mechanism, i.e. magnetic or electrical. Ultimately, the researcher finds that a combination of factors influenced the children's observations. Age was a primary factor, but other factors included previous knowledge and social interaction. 
An interesting example of a study that integrates garden-based education with development of observation skills is a 1996 piece by Mabie and Baker that finds that children's skills were positively affected both by integrating a garden project into a science curriculum and by using short in-class agricultural projects. Their research studies the effect of experiential education on the science process skills of 147 urban fifth and sixth graders over a period of ten weeks.

Mabie and Baker explore the students' ability to observe, communicate, order, relate and infer. Students completed several tasks designed to test the relevant skills, such as observing and describing an un-popped piece of popcorn, then comparing it to a popped one. A total of five evaluations were used. Students then spent ten weeks working on science curriculum as part of three treatment groups: the garden group, the in-class project group, and a control.

The garden group spent ten weeks establishing and maintaining a vegetable garden, during which the researchers (who also taught the treatments) encouraged them to use their science process skills in ways such as observing and comparing soils and pest problems. The group spent one hour per week for the ten weeks on garden lessons. The in-class project group also spent one hour per week on their experiential activities, but they participated in three projects that were completed within the classroom. This treatment spent three weeks each on germinating seeds, baking bread and hatching chicks. The students received the same type of science process skills instruction as the garden group did, in being asked to observe bread and compare it to other baked products, etc. The third group received traditional lecture-type instruction over the ten 
weeks and was taught by the teacher, who was instructed not to provide any special focus on the science process skills.

After the treatment period the students were asked to perform the same tasks as before, and their responses were compared to their pre-treatment answers to determine if there was improvement and, if so, the extent of the improvement. In the first task, in which students were asked to describe un-popped popcorn, all three groups showed improvement, with the control showing $46 \%$ improvement and the garden and in-class groups showing $55 \%$ and $62 \%$ respectively. When the groups were asked to compare the popped and un-popped popcorn, the control, garden, and in-class groups showed 27\%, $48 \%$, and $53 \%$ improvement respectively. These two tasks were designed to test the students' observation, comparison and communication skills. Results were wildly variable on the rest of the tasks, designed to test the other science process skills.

The differences in results between tasks and between groups within the tasks make the data difficult to generalize. What can be said is that groups that received one of the treatments did show gains in all tasks, and that in general the in-class group showed more improvement than the garden group. The researchers posit that this differential may be explained by the difference in duration between the projects. The in-class group participated in short projects that were begun and completed during the study, while the garden project is ongoing. Additionally, the authors question why the control group exhibited declines in some of the tasks. Perhaps competency in these skills is related to motivation, and students who did not participate in experiential education lost interest and thus motivation? Finally, the authors are careful to note that this study may have external validity issues because the demographic was so narrow (two schools were 
studied - one 99\% Hispanic and the other 25\% Hispanic and 75\% African American.)

Future research with more diverse populations may be warranted.

While much of what is being implemented in classrooms currently is content centered, research shows that students need not only content knowledge but also important scientific skills and practices in order to fully understand the broad concepts that they need in order to become truly science literate. These skills and practices, such as observing, comparing, and describing, are the foundation that students build on to develop their higher order thinking skills. Although the skills and the content knowledge building support one another, especially in inquiry activities, students also can benefit immensely from practicing their skills individually.

\section{Summary}

Across the literature, links between these three lines of research arise frequently. The importance of experiential education appears in all three, as does motivation. Solid observation skills are shown to be necessary for students to progress to higher order cognitive skills, and school garden experience is shown to support those same higher order skills. Across research on science journals, their contribution to providing an authentic context for students is often cited as a rationale for usage; this authentic context is one of the key factors in producing high quality observations according to Eberbach and Crowley (2009). Finally, all three components - school gardens, journals, and practicing observation - are common and effective features of science curricula.

The goal of this intervention was to improve students' observation skills. Although Mabie and Baker (1996) found that short in-class experiences were as effective 
at improving science process skills, and in some cases more effective, I chose to implement this in a school garden setting. Mabie and Baker's work explored a broader spectrum of outcomes by focusing on all the science process skills, and also was done with a very different demographic than the one in this study. My belief is that students who have had ongoing exposure to experiential education through a garden program will experience the positive attitudes mentioned in so many studies, which will be a strong motivator. Motivation was mentioned in several studies, including Mabie and Baker, as potentially being a critical factor in producing rich observations. Kellert's (2002) argument, that the unpredictable nature of the garden attracts children's attention, is another factor in choosing to situate this study in a garden. Common sense dictates that students will be better able to produce high-quality observations if their attention is focused and sustained.

Science journals are an integral part of this study, both as an assessment tool and as an aspect of the treatment. The expectation was that the use of the journals wl have a positive effect on the students' ability to make and record observations. Research shows that transforming their scientific observations into their own words allows children to make these observations more personal and meaningful; this ties closely into the experiential learning theory so prominent in garden literature. Journal writing also supports the push toward allowing students to act as scientists in an educational setting. It is important for children to see that making good observations and recording them well is a fundamental part of the scientific process, and to see that they are capable of acting as a scientist does and of using the same tools. 
The journals are not only valuable as a tool for students, but also for the researcher. Student journals are a rich source of data for a researcher, allowing students of different abilities, cognitive preferences, and language skills to demonstrate what they know and can do on an open-ended, student-led platform. The somewhat ambiguous nature of student journals can lead to challenges in evaluation, but Shepardson (2001) and others provide age-appropriate assessment tools that address the three criteria selected for this study.

These criteria were based principally on Eberbach and Crowley's (2009) work, but with some confidence as each criterion emerged as a recurring theme across the literature. Two other common themes were the importance of developing observation skills, and incongruously, the lack of time and attention devoted to this skill in most classrooms. Research found teachers of younger students often did not intentionally teach observation as a skill, and that teachers of older students frequently assumed that students already knew how to do it. Nowhere in the sequence of elementary school were students getting deliberate instruction on how to put this into practice successfully. One of the key components of this study is that students are given specific instruction on the aspects of scientific observations, and the opportunities to watch the process being modeled, and to practice the skill themselves in an authentic context. 


\section{$\underline{\text { Methods }}$}

Overview

The question this study addresses is whether the use of science journals in a garden setting can have a positive effect on elementary students' observation skills. The study follows a mixed-method, quasi-experimental format presented in the form of a case study, as the study includes one population with 28 participants and no control group. This follows Blair's (2009) suggestion that future research on the effects of school gardens would benefit from including both quantitative and qualitative data. This study aligns with design-based research, as the intention is not to compare performance between two groups; rather the goal is to evaluate the efficacy of the treatment, to gain knowledge about the strategy utilized, and to provide a foundation for potential further iterations of the research.

Gains in students' ability to make high-quality scientific observations are determined based on performance on pre- and post-assessments. Students' science journal recordings and interview responses provide rich qualitative data. Three criteria are used in assessing student work: Accuracy, Detail, and the Inclusion of Quantitative Data. These criteria are based on work by Shepardson and Britsch (2001) and Eberbach and Crowley (2009). Accuracy refers particularly to the ability to capture the true nature of the artifact that the child is observing. For example, recording an accurate number of petals rather than a random assortment, or the exact shape of a leaf rather than a generic oblong shape. Detail refers to the types of observations noticed and recorded. For example, did the student refer to a petal as simply "yellow" or did the student use rich language to describe the color or compare it? Did the student notice the different sizes 
and directions of the veins of a leaf, or simply draw the margin? The Inclusion of Quantitative Data refers to the intentional recording of any type of quantitative data about the artifact. Examples would include measuring height of a plant, counting the number of petals on a flower, or estimating the weight of a pumpkin.

During the course of this study, the researcher also served as a student teacher in the classroom, and all learning opportunities were presented by the researcher. Lessons were presented as a regular part of the science curriculum of the class, journal entries were evaluated as data for the study but were not graded, and students did not receive formal feedback on their work.

Study Site

This study took place in a K-8 school ("Summerland"*) located in a large metropolitan city in the Pacific Northwest. Summerland School is a "focus option" school with a focus on math and science. Entrance to the school is through an automated lottery system, so students are not required to test in to the school, nor are they automatically accepted based on residency. Parents must choose to enter their child into an automated lottery, and students are admitted at random with the exception of siblings of current students, who are automatically accepted. In kindergarten, 24 students are admitted, but often less than 10 spots are actually available for new families after slots are filled by siblings. In first grade, an additional four new students are admitted. Each grade level in the primary grades has only one class. 
In the year preceding the study, Summerland had 346 students. Summerland has low ethnic diversity compared to many of the neighborhood schools surrounding it, with White students making up $80.3 \%$ of the population in 2012 .

Figure 1. Racial/Ethnic Background, Summerland School, 2012.

\section{Racial/Ethnic Background, Summerland School, 2012}

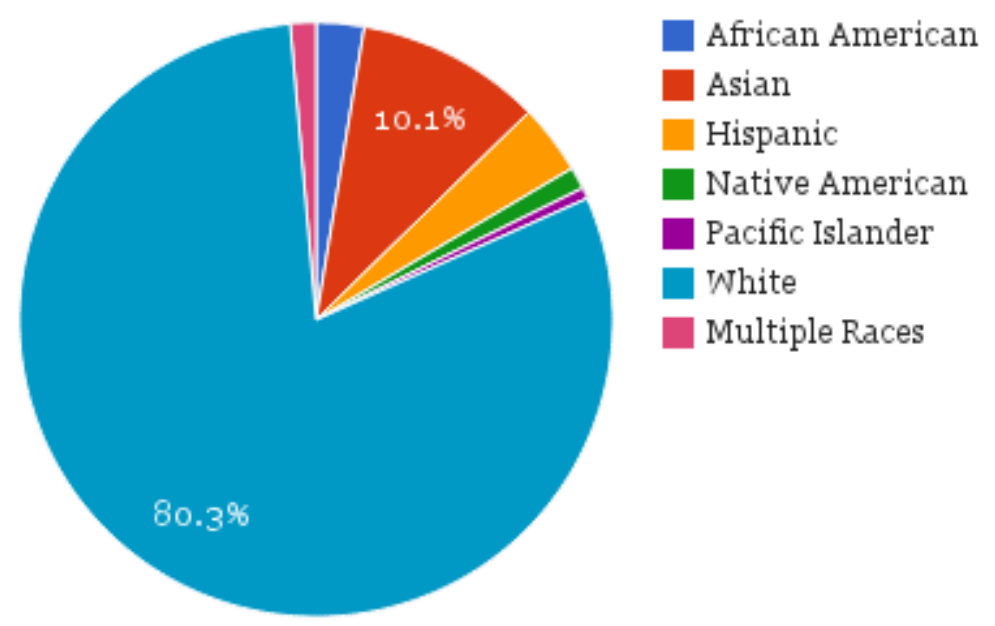

The students at Summerland have consistently produced outstanding test scores, with over 95\% Meeting or Exceeding state benchmarks in both Reading and Math at third, fifth and eighth grades, with the exception of third grade math at $90 \% .46 .2 \%$ of the students are identified as Talented and Gifted (TAG). Because the school draws from neighborhoods throughout the metropolitan area, it is difficult to determine socioeconomic demographics; however it can be said that only $9.2 \%$ of the students receive free or reduced lunch and that the school does not receive Title I funding. This 
school was chosen as the site for this research because it is the researcher's field placement for student teaching.

Summerland has a vegetable garden as well as other plantings on the campus that are maintained by the fifth grade class. Although all teachers and students have access to these planted areas, they are rarely utilized by anyone other than the fifth grade class. This study was conducted during the fall months, so by regularly visiting the garden the participants witnessed the process of harvesting and preparing the garden for winter. Sunflower plants were harvested for seeds, pumpkins on the vines disappeared between two visits, and many other changes took place that the students keenly observed.

\section{Participants}

This study took place in a class with 28 second grade students between the ages of seven- and nine-years-old, of which nineteen were boys and nine were girls. The racial/ethnic background of the classroom reflects the overall diversity of the school, with White students in the majority. The selection process for participation was based solely on the students' enrollment in the researcher's field placement and parent permission. For inclusion in this study, students were required to have parent permission, complete pre- and post-assessments, and participate in four instructional opportunities. Every student in the class met all the requirements $(\mathrm{N}=28)$.

Although Summerland does have a rigorous course of study and overall high academic achievement, achievement within any individual class does fall on a continuum. TAG testing begins at second grade, so an accurate number of TAG students in this class is difficult to estimate, but at time of writing 20 out of the 28 students had 
been nominated. One student in the classroom has an Individualized Education Plan (IEP) for a communication disorder related to autism and one other student is in the process of being evaluated for the same diagnosis. There are no English Language Learners in this classroom, which is typical for Summerland but atypical for the district and neighborhood in which the school is located. Students were assigned a number between 1 and 28 for purposes of confidentiality, and students were given pseudonyms for confidentiality during the interview portion. Access to other participants to form a control group would have been prohibitively complicated in this setting, as would randomizing the participants.

Although this group of students was familiar with the vegetable garden on campus, they had never received any academic instruction in the garden. Many of the students did express that they had vegetable gardens at home that they worked in. Students also had had limited exposure to recording in science journals.

This study was conducted in the researcher's student teaching classroom, under the supervision of the researcher's Cooperating Teacher, Mrs. Arnold. Mrs. Arnold has taught at Summerland School for fifteen years and has taught both first and second grades.

In keeping with case study methodology, interview participants were not selected randomly, but with the intention of representing a variety of overall achievement in the class and specifically on the study instruments. 


\section{Procedure}

This study took place during the months of September and October, 2012. Each week, students received direct instruction and witnessed modeling inside the classroom on how to record scientific observations, and then were given an opportunity to practice those skills outside in the vegetable garden. Pre- and post-assessments were conducted the weeks prior to and following instruction.

During Week 1 (W1), students were introduced to the criteria on which they were being assessed and asked to record their observations in the garden using only writing. During Week 2 (W2), students were reminded of the same criteria, but were asked to record their observations with only drawings, although labels were encouraged. Students were specifically asked to begin their recordings on a macro scale, drawing the entire plant that they were observing, then to move progressively smaller, next recording one piece of the plant and finally, one even smaller piece of the plant using a jeweler's hand loupe. Students also had the opportunity to use this loupe during Weeks 3 and 4 (W3,W4), and both the pre- and post-assessment.

During Weeks 3 and 4 students were given the opportunity to integrate the two methods of recording and were given more specific guidance based on their previous recordings. Students were also encouraged during W3 and W4 to include quantitative observations as well as qualitative and were given access to rulers for measurement purposes. These learning opportunities all took place on Tuesday afternoons for approximately one hour at the end of the school day. See the appendix for a unit outline with more detailed lesson plans. 
Instruments

Students' observational skills and the gains in those skills were assessed using three instruments.

- Performance on a pre-assessment measured students' baseline observational skills one week previous to the treatment. Students completed the same post-assessment one week following the treatment. Performance was assessed based on a rubric developed by the researcher for this study.

- Student journals offered rich qualitative data, a method of assessing performance gains throughout the time during which the treatment occurred, a contrast between the types of observations students recorded in the garden versus inside the classroom, and finally, evidence of the types of recordings students produced having explicit instruction and guidance immediately previous, versus an assessment format with no teacher interference.

- Student interviews were conducted in order to gain more insight into students' cognitive processes during the treatment, their intentions in their observational recordings, and information about their individual backgrounds and history.

The cooperating teacher and another science education researcher evaluated all instruments and assessment tools in order to ensure reliability and validity. 


\section{Pre- and post-assessments}

During the pre-assessment (P1), the researcher provided each student with a fresh leaf and the instructions to record their scientific observations about the leaves in their science journals. No information about the criteria against which their entries would be evaluated was given. Students were given 30 minutes to complete the activity and were told that their observations could be written or drawn, and that if they were drawn they could use color. No other explicit instruction was given. Students were asked to tape their leaf into their science journal, so that the researcher could evaluate the assessments for accuracy.

Following the activity, the assessments were photographed using a digital camera with a small marker noting the student's confidential identification number and assessed using the Assessment Rubric.

The post-assessment (P2) was conducted in the same manner, with each student provided with a fresh leaf and given the instructions to record their observations like scientists and with reminders that they could use both written and drawn records and color if they chose to draw. Students were again given 30 minutes to complete the task. The post-assessment was also evaluated using the Assessment Rubric.

The Assessment Rubric was designed specifically for this study and was evaluated for validity and reliability by a fellow science educator and a fellow science researcher. These two peers and I independently scored multiple student samples independently and compared scores, finding scoring strategies consistent throughout. I also scored random samples of student work myself multiple times, achieving consistent results throughout. The rubric assessed student work in terms of Accuracy, Detail and 
whether the student included Quantitative Data. The Assessment Rubric underwent many changes before its final incarnation. Accuracy, Detail and Quantitative Data were always key features of the rubric, but other categories were considered as possibilities for assessment. Based on findings in the literature, the rubric at various points included Relevance, Thoroughness, and Use of Scientific Vocabulary (Shephardson and Britsch, 2001; Eberbach and Crowley, 2009.) In one incarnation, the rubric assigned points based on the inclusion of both written and drawn recordings, as this was a focus of the treatment, as well as including specific types of data that students were expected to record (Shape, Color, Size and Texture.) However, that version of the rubric was impossible to apply to the weekly journal entries, as two of those weeks excluded one type of recording, and some of those qualities are much easier to record in one form or the other. For example, it is easier to use a descriptive term such as "fuzzy" or "sticky" to indicate texture, while it is easier to capture the shape of a leaf in a drawing rather than in words. Based on many conversations with colleagues, the final Assessment Rubric emerged. Although it is far simpler than some of the previous versions, this rubric narrows the scope of the research to its true center, thus more clearly revealing the results. See Appendix B for the Assessment Rubric.

\section{Student Journals}

As part of the treatment, students recorded observations once a week in their journals. Some expectations of the journal were consistent throughout the project (i.e., basic field information such as time, weather, and location) and some elements were specific to the entry. These journals are also used in the classroom during other science 
activities, particularly as a place to record "loupe lists". As part of Mrs. Arnold's curriculum, the students sometimes use their jeweler's loupes to closely inspect an object and write a list of things of which they are reminded, or to draw what they see through the loupe. The intentions of these activities are more literacy and art than science, however the science journal is where they do their recording. The science journals are small green notebooks distributed by the school district within which Summerland is located. The pages of the journals are graphing-style paper, and during this activity no specific prompts or sentence starters were provided.

Materials with which students could color their drawings were not available during the outside experience, but students were given time upon returning to the classroom to color if they wanted. The vast majority expressed no interest in coloring their work on most days.

\section{Student Interviews}

Fourteen interview participants, half the class, were chosen to represent certain categories based on either gains between pre- and post- assessment or on baseline score on the pre-assessment.

1. Students who made a gain of over five points.

2. Students who gained between one and five points.

3. Students who made no gain.

4. Students whose scores declined from the pre assessment to the post assessment.

5. Students who scored fifteen or over on the pre-assessment.

6. Students who scored between ten and fifteen on the pre-assessment. 
7. Students who scored below ten on the pre-assessment.

A selection of core questions was given to every interview participant. Some questions were intended to explore what effect the students' past experiences with gardens or garden education, with scientific observations, or with science journals may have had on their experience during this study. Other questions were designed to give the students an opportunity to reflect on their experience and share anything that might be difficult to decipher or understand from their journal entries, as these are young students who are still developing their writing and drawing skills. Their intentions may not always be obvious from what is on the page. Finally, a subset of questions explores what the students now know, think and feel about scientific observations. These interviews were conducted during the month of January 2013. Students were interviewed individually during school hours over the course of one week and were audio recorded. Refer to the appendix for the complete list of interview questions. 


\section{RESULTS}

The results section is organized according to the categories on which students were assessed according to the rubric: Accuracy, Detail, and the Inclusion of Quantitative Data. Within each of these categories, information is included from pre- and postassessments, journal entries and interviews.

Scores improved from the pre-assessment to the post-assessment in all three categories, with the greatest improvement in the Detail category.

Figure 2. Average Performance on Pre- and Post-Assessments

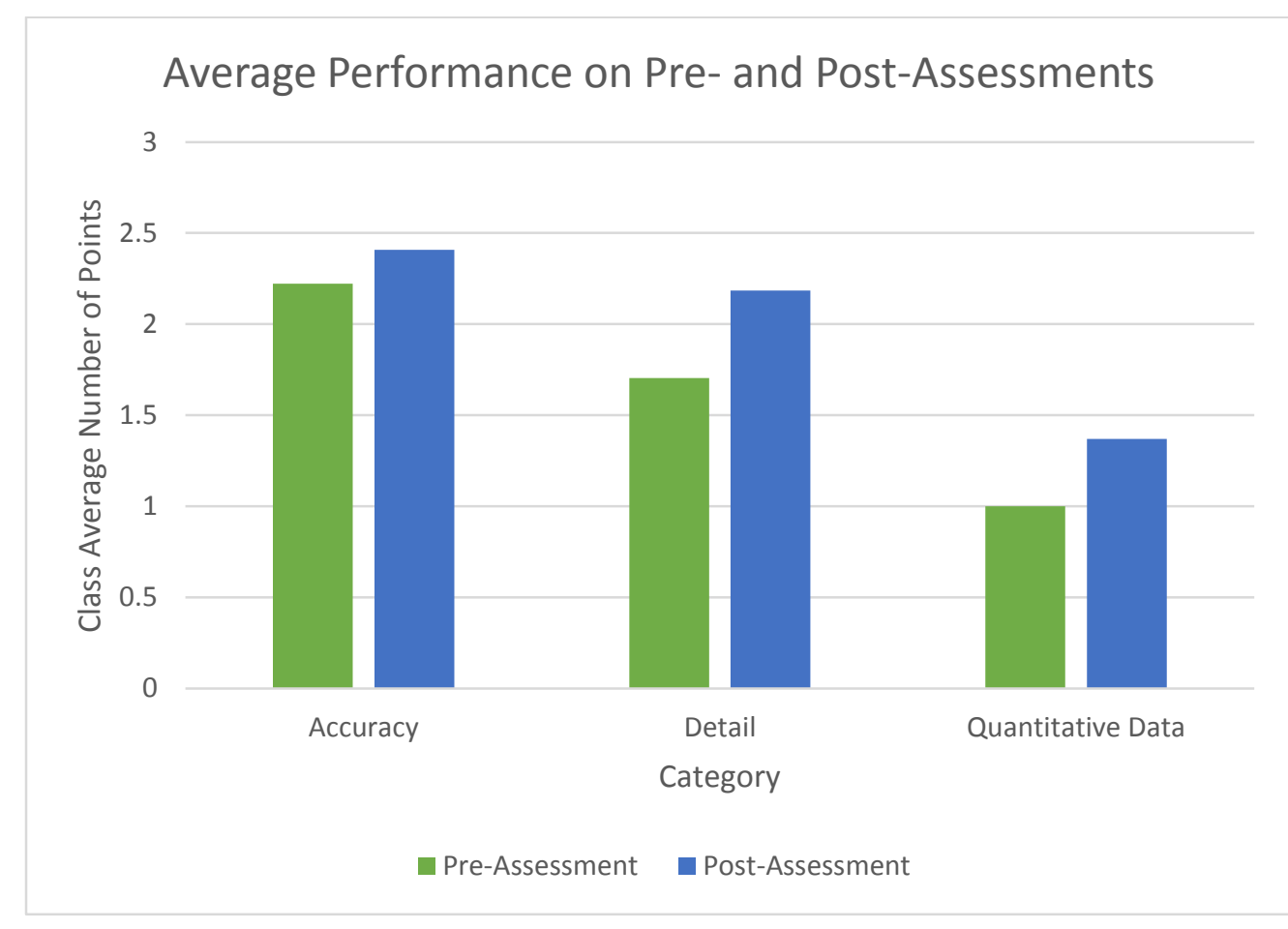

Journal entries for all four lessons were scored using the same rubric for all fourteen interview participants. 
Figure 3. Performance on Journal Entries

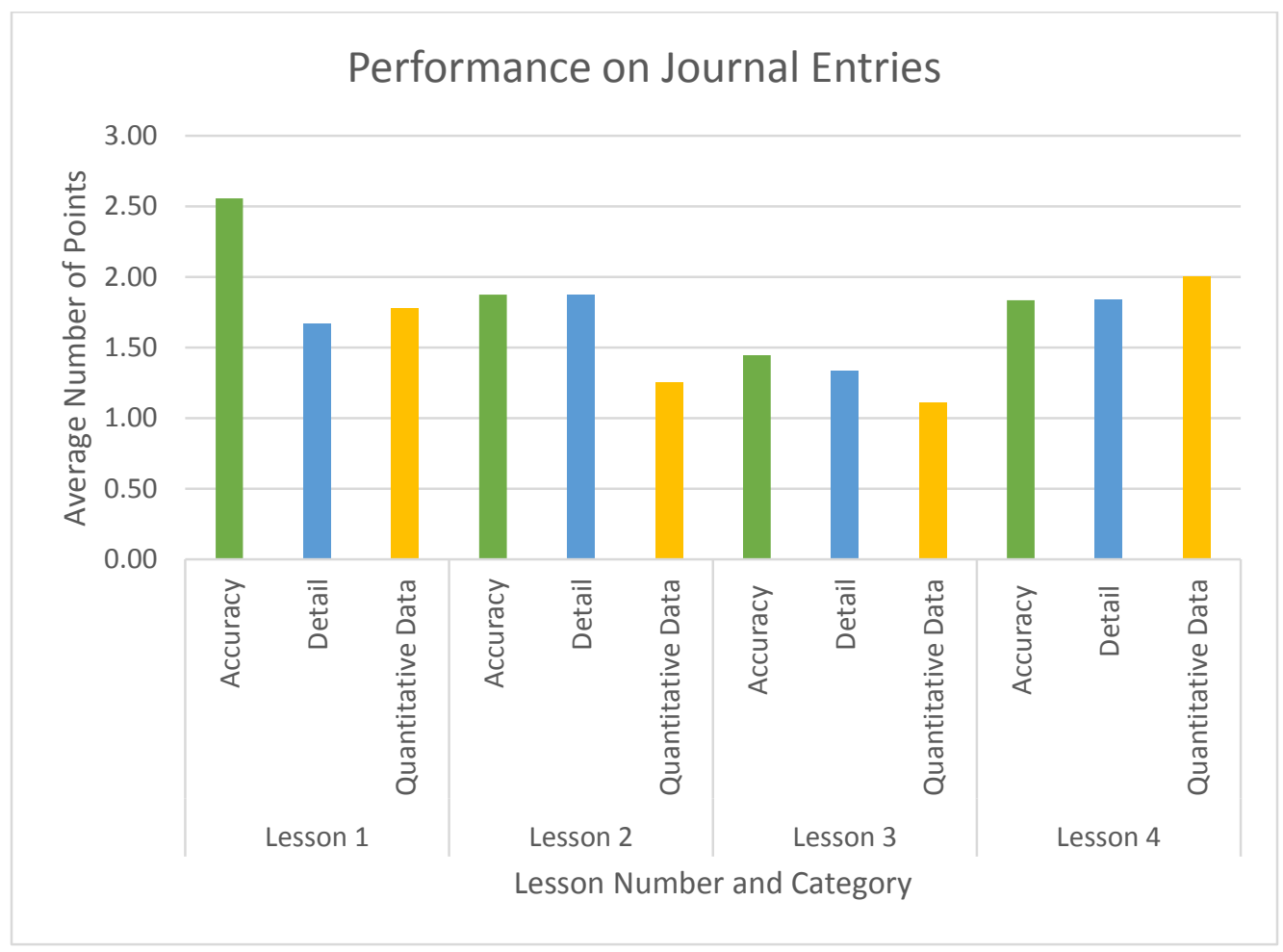

Interview results for the fourteen participants were evaluated for relevance for the three rubric categories. Detail was the most common of the three, with three students referencing detail during their interviews. Quantitative data and Accuracy were referenced in one interview each.

\section{Accuracy}

Scores on accuracy on the pre-assessment were overall much higher than expected, based on the findings in the literature (Shepardson and Britsch, 2009) that young students' observations were often highly inaccurate. The overall class average was 2.22. The class average improved to 2.41 on the post-test, an $8.6 \%$ change. A t-test returned a p-value of .13, indicating that these results are not statistically significant. 
Figure 4. Performance on Pre- and Post-Assessment (Accuracy)

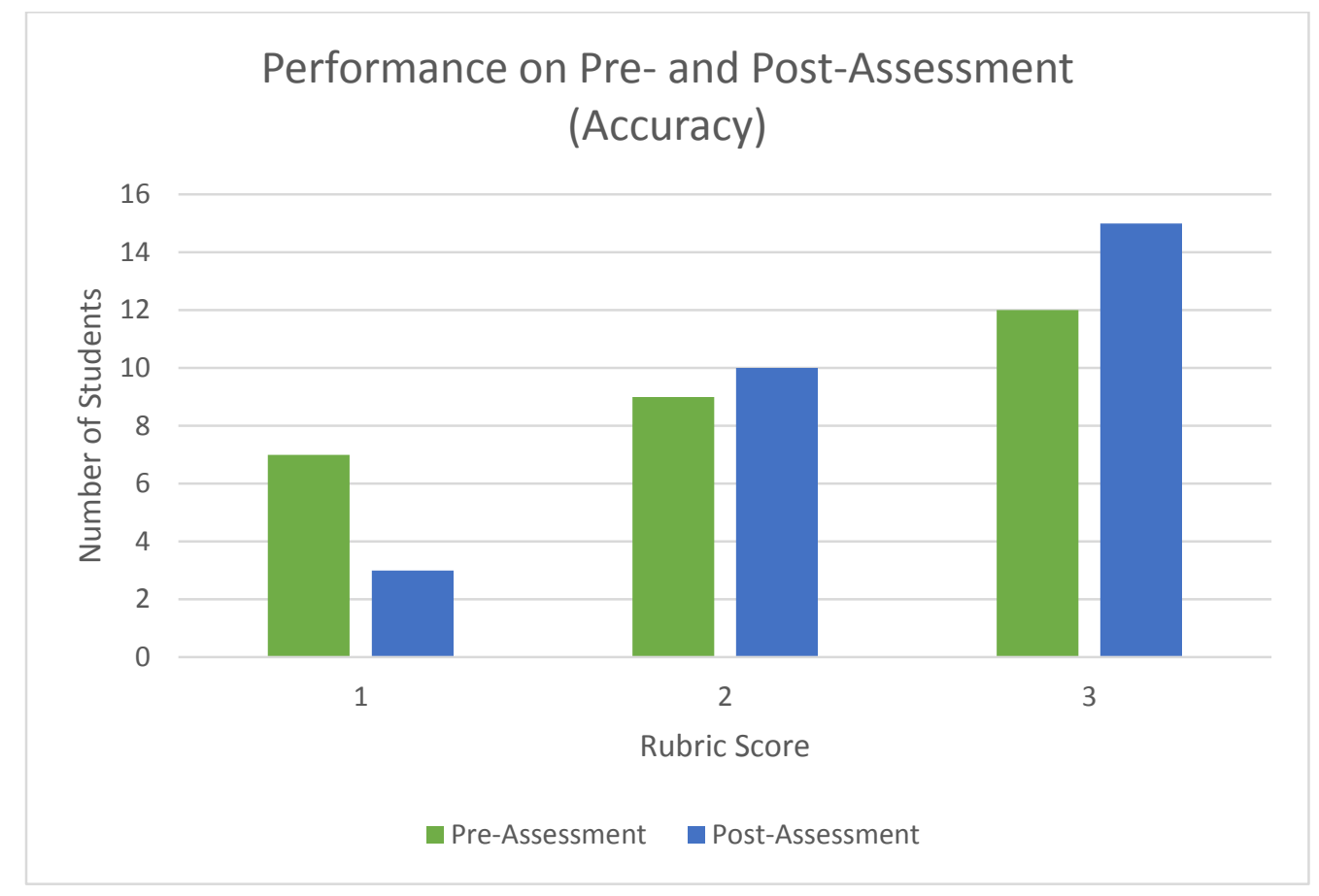

During the interview process one student addressed the topic of accuracy. When asked, "Do you think it's important to make good observations when you are doing science?" Declan replied, "Yeah, because you get an accurate answer."

\section{Detail}

Student performance in the Detail category showed substantial gains. The class average on the pre-assessment was 1.70 , increasing to 2.19 on the post-assessment, a $28.8 \%$ increase. A t-test returned a p-value of .003 , well below the level needed to claim statistical significance. 
Figure 5. Performance on Pre- and Post-Assessment (Detail)

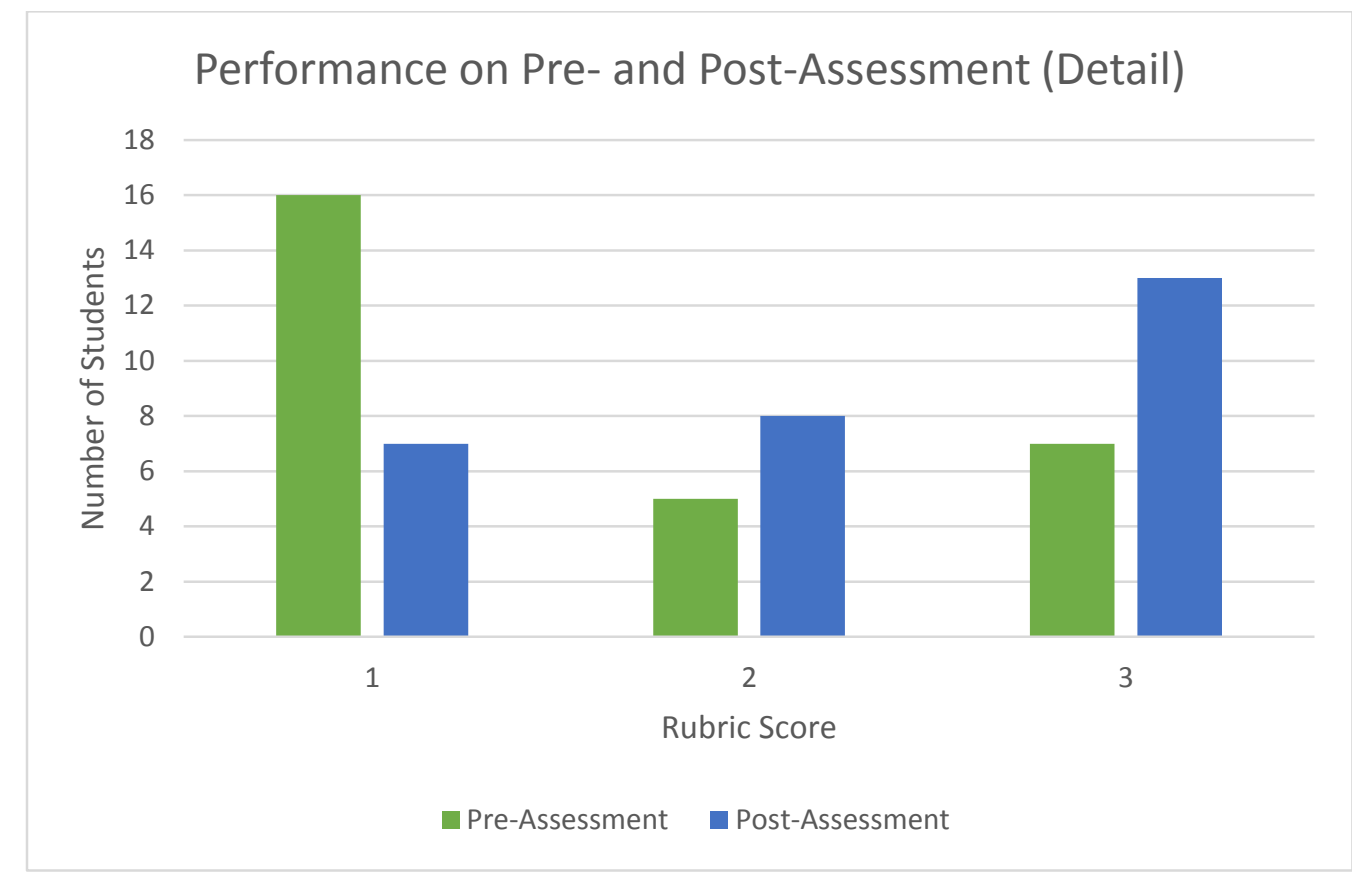

For some students, observations consistently increased in detail throughout the process. For example, Ellie received a 1 on her pre-assessment. Her journal entry was a simple written statement: "I see pounts around the end. I love the veins on the leef. My leef is turning brownish black." A small drawing of the leaf was erased, so I chose not to include it in the scoring of the artifact. 


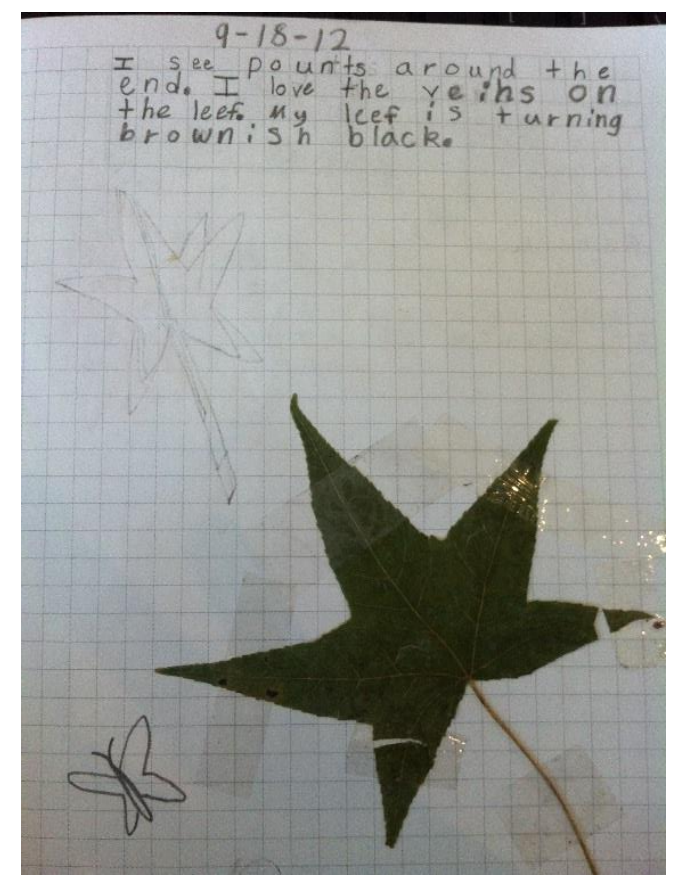

Ellie's next entry, on a day when the students were asked to use words only and not pictures to record their observations, says, "It smells like potato skin. Part of the plant turns yellow. It's calld a cosmo. The leev's are thin. The stems are relly fat. The metle stem is on the plant. The metle stem is atachd to the thin stems."

Ellie's next entry, on a day when students were asked to draw rather than write, is two drawings. One drawing is of the whole plant, with six pink and yellow flowers and green feathery leaves. The other drawing is a close up of one flower, with an incredibly detailed representation of the center. 


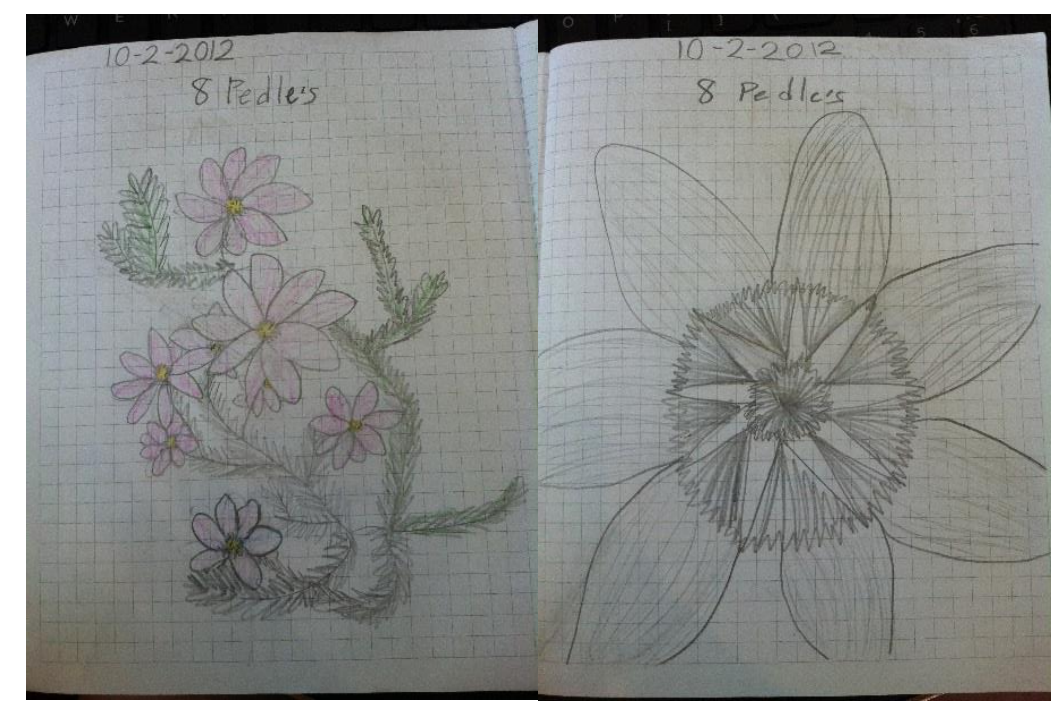

Ellie's post-assessment combines those two processes, with both detailed writing and drawing. Her text reads, "There are 18 little spikes. It is yellow. It has line's all over it and they all go deferent diricsions. It is partly yellow and a little bit of brown. It has lots of details. It reiminds me of...The sun. some dirt. A road. Yellow stone.) She also includes a small drawing of the leaf. Although the drawing is not to scale, it is amazingly detailed, with yellow and brown shading that accurately represents the leaf. She received a 3 for her post-assessment. 

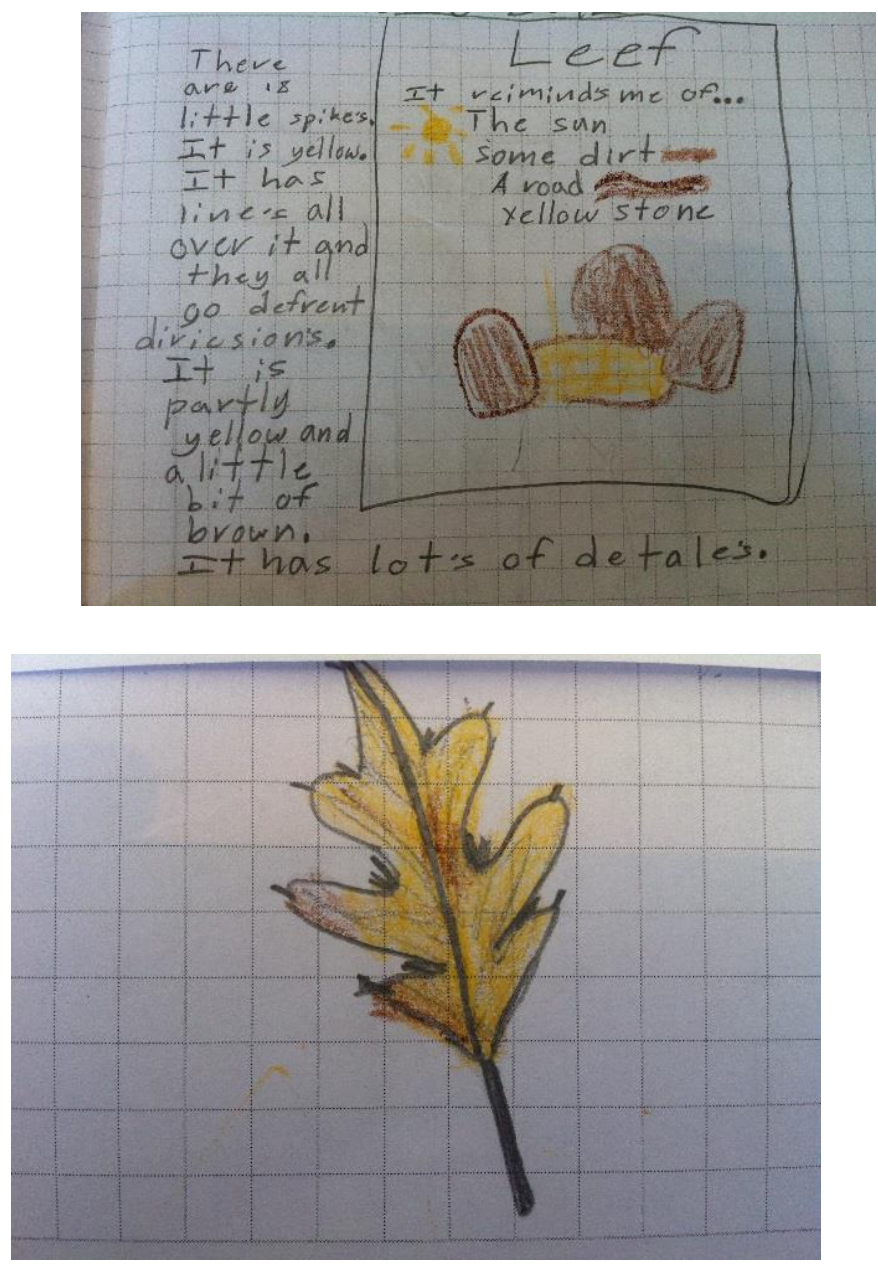

Other students' observations increased in detail, but more sporadically. Steve's pre-assessment is a very accurate representation of his green leaf, but only has fair detail. The drawing is primarily green, although upon closer inspection one can see that he attempted to draw the veins in yellow but they are overwhelmed by the green marker. However, he ignores the serrated edges and a large missing chunk of the leaf. The sole text reads: "it is a maple lyfe." 


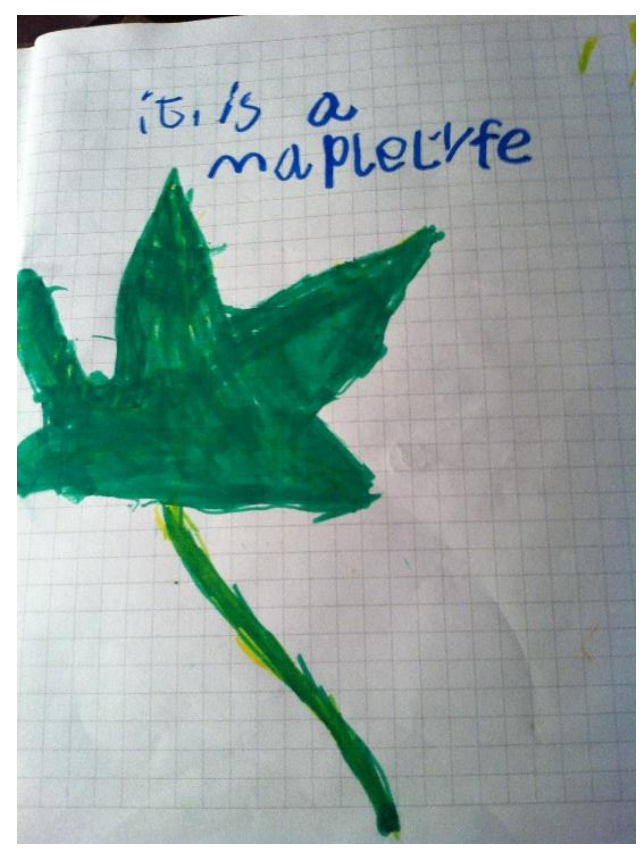

His next entry, on the day they were asked to write, simply reads, "it smels like lavindr." However, his entry for the day on which they were asked to draw shows great thought and care and a much higher level of detail than any of his previous entries. On this day, Steve drew three pictures, one of the whole plant, one of an individual flower, and finally a close-up view using his jeweler's loupe. Each picture increases in detail. This is the most detailed example of Steve's work. 


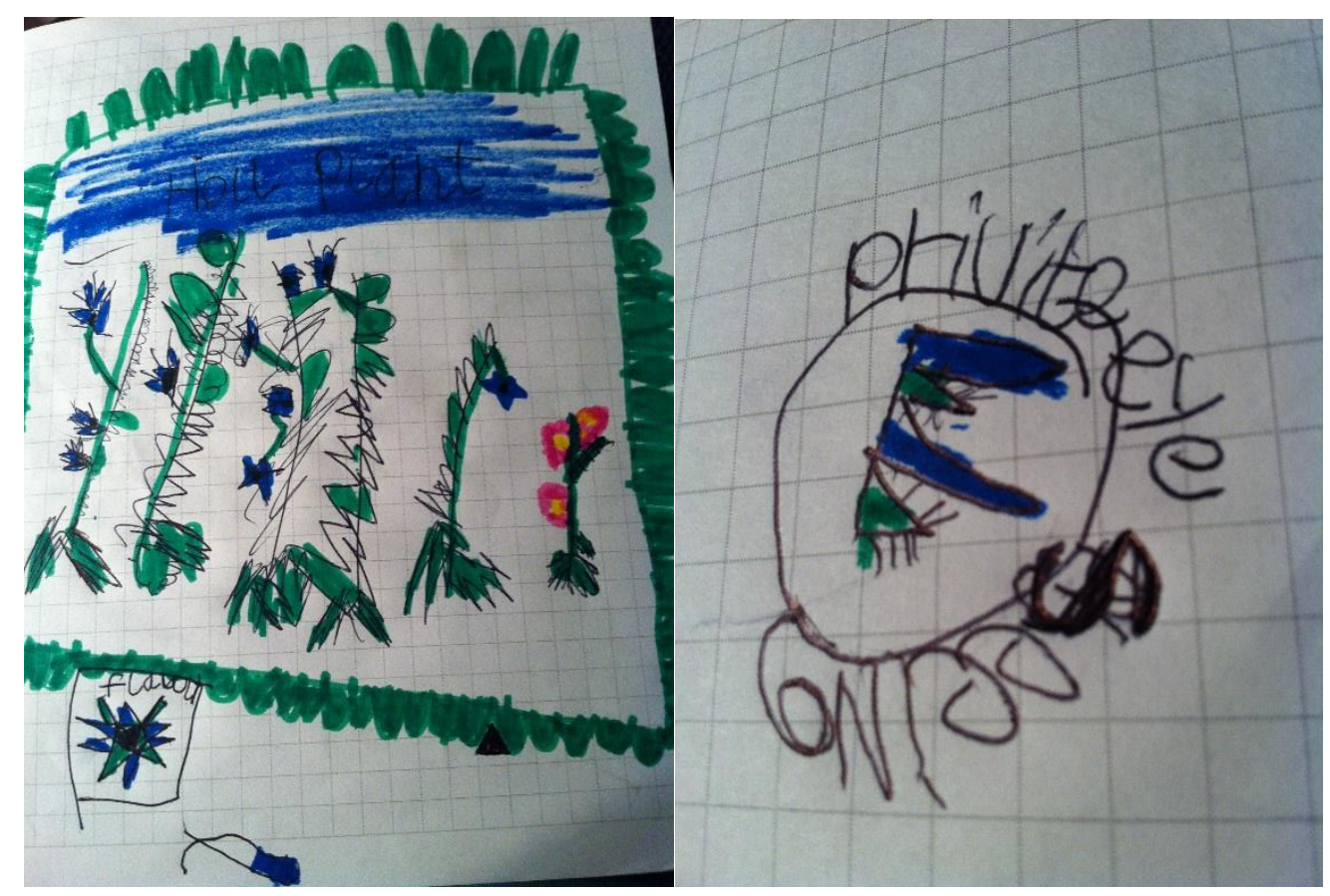

His post-assessment is a vast improvement over his pre-assessment, with two drawings, more detailed use of color to indicate veins and small features of the plant, and a detailed representation of the shape of the leaf. His score improved from a 1 on his preassessment to a 3 on his post-assessment. However, it does not approach the detail of his second journal entry.
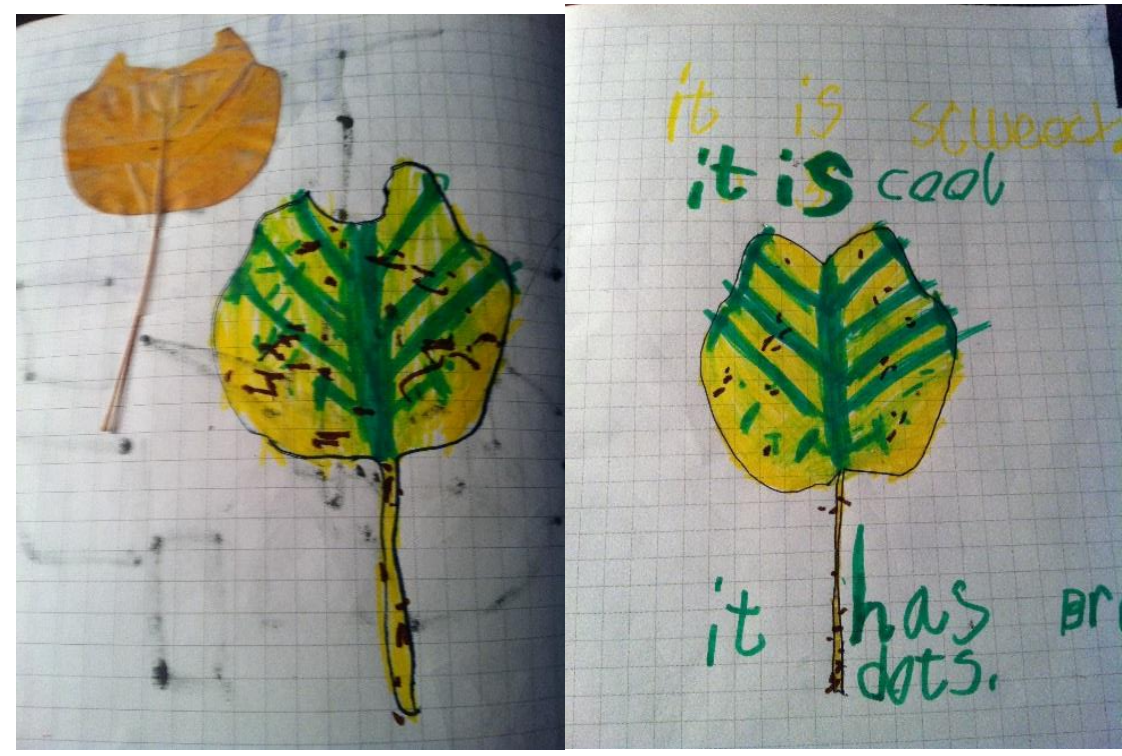
Detail was a common theme that emerged during the interview process. When asked what makes a good scientific observation, three of the fourteen interviewees mentioned detail.

Table 1. Examples of student responses to the question, "What makes a good scientific observation?"

\begin{tabular}{|l|l|}
\hline Student & \multicolumn{1}{|c|}{ Response } \\
\hline Vicenzo & $\begin{array}{l}\text { "If you notice it and you try to } \\
\text { look very closely at it and record the tiny } \\
\text { details." }\end{array}$ \\
\hline Ben & $\begin{array}{l}\text { "Using all of your senses that you } \\
\text { can and trying to observe as much detail as } \\
\text { you can." }\end{array}$ \\
\hline Roger & $\begin{array}{l}\text { "Looking at it closely. Making it } \\
\text { really detailed." }\end{array}$ \\
\hline
\end{tabular}

\section{Quantitative Data}

Student performance in the Quantitative Data category also showed substantial gains. Not a single student included any kind of quantitative data on the pre-assessment, resulting in a class average of 1 . The class average on the post-assessment was 1.37 , a $37 \%$ increase. A t-test returned a p-value of .022, indicating that these results are statistically significant. 
Figure 6. Performance on Pre- and Post-Assessment (Quantitative Data)

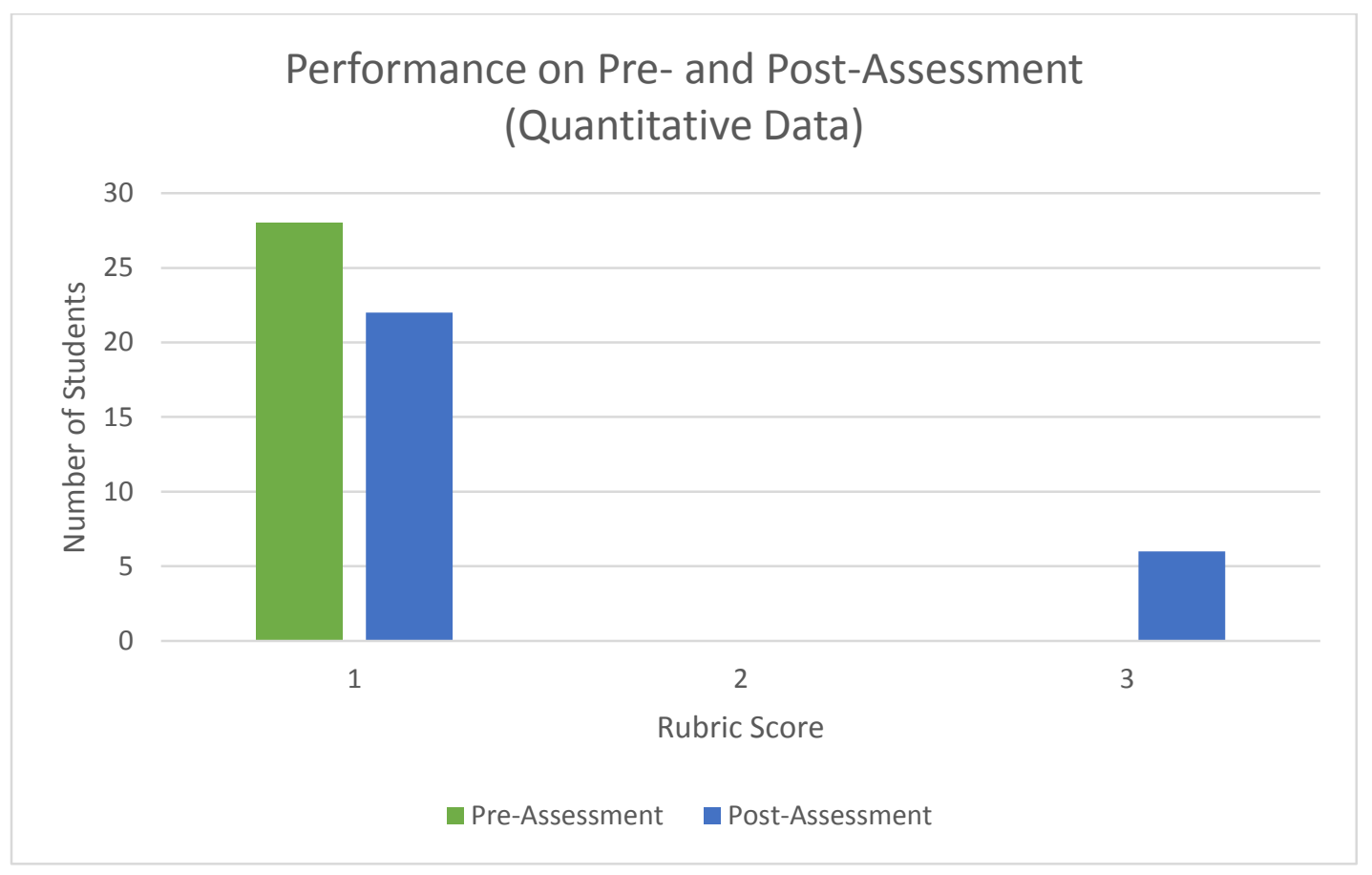

While only two of the interview participants included quantitative data in their post-assessment, nine of them included quantitative data on one or more of their journal entries. For example, Roger's entry for Lesson 1 reads, "54 petals. Pink Petals. Brown/green stem. Leaf - 9 main veins, 124 side veins." When I asked Roger if he had counted every single petal and vein, he responded with a vigorous, "Of course!"

Although Ben did not include any quantitative data on his post-assessment, he did in all of his three journal entries (Ben was absent for one lesson). Lesson 1 reads: "I saw cosmo flower leaf. It had stiff and slender leafs that smelled like tomatos. It hade one main vein six secondary veins it had 42 other veins it was sticky it grows flowers it was drak green it was as big as an egg." Lesson 2 is a colored diagram of a plant with the 
label: "about ten in. long". Lesson 4 is a map of where his plant was located and includes a small drawing of his flower with the text "1 inch" and " 28 inches tall."

One student addressed the inclusion of quantitative data during the interview process. When asked the question, "What makes a good scientific observation?" Sadie replied, “Um, I think it's nice um like to - if this wasn't here you couldn't quite tell what it looks like even from the drawing so I think it's nice to like, maybe put a labeled diagram of the color and if there was a bug on it you might even put like, There was a bug on this plant, I think it was a so and so. And so you could write down the colors, you could write down what shape it looked like, you could write down if there are any spots and if there are some little spots then you could count them, or you could estimate how many spots if there were a lot or you could estimate how old the leaf was." 


\section{DISCUSSION}

This study was based on several founding premises. The literature review showed that the ability to make high quality observations is critical when doing science, both for children and for adults, but that elementary age students were, for the most part, not receiving the support that they need in developing this foundational skill (Eberbach and Crowley, 2009.) My belief, again based on the literature (Eberbach and Crowley, 2009), was students were not receiving any explicit instructions on how to do this, and that this type of explicit instruction would result in higher quality observations. I also believed that students' observations would increase in quality if they were highly motivated, and that working outside in the garden and using science journals were two ways to increase student motivation. This culminated in the research question, "Does the use of science journals in a school garden setting improve students' observation skills?"

This study adds valuable information to all three lines of research that were used to develop its theoretical basis. Blair (2009) put forth that more research was warranted to continue exploring the relationship between school gardens and children's understandings of science. The findings from my study show that a school garden experience can improve children's observational skills. The ability to make and record high quality observations is critical to a child's overall ability to act as a scientist, as observations are vital in developing testable questions and in successfully recording data during inquiry (Eberbach and Crowley, 2009.) These results add to a body of literature that continues to demonstrate the myriad benefits of school gardens.

This study also provides fascinating insight into the students' experiences with science journals. The interview process revealed that only one student in the classroom 
remembered ever having used a science journal before this experience. However, the students were very enthusiastic about their journals and continued to use them throughout the year, often without prompting, to record observations. During the interview process, two students discussed their continued usage of science journals at home. Elliott mentioned that although he had been keeping science journals at home for some time, this process had changed the way in which he used them. Fiona mentioned that she had never had a science journal before, but that since we began doing our observations that she had started keeping one at home. Clearly, once the science journals were introduced as part of the study, students took ownership of them and developed a habit of using them. Although the final data was collected for this study in October, I continued to monitor these students' science journals throughout the school year, and can attest that student performance in them continued to improve throughout the year. Our usage of the journals very much followed the ideas of Mcquitty et al (2009) and Aschbacher and Alonzo (2006). Journals were used according to a knowledge transforming model, rather than as a writing-to-communicate strategy, and moderate guidance was given. Students had some expectations of what to include in each journal entry, such as basic field data, and certain types of observations were encouraged for each entry, such as quantitative data. However, students received no specific prompts or sentence starters, and were allowed to organize their observations in whatever way they saw fit. Students were encouraged to record their observations in ways that would help them make sense of the experience, rather than to communicate their learning to another person. Students were told that they would not be evaluated on grammar, spelling or punctuation. Students' 
continued improved performance in recording their observations in their journals supports the theories put forth by these two sets of researchers.

Finally, the overall result of the study shows that students' observation skills can indeed be improved by the use of science journals in a school garden setting.

Accuracy

My review of the literature indicated that students' scientific observations were often inaccurate. Eberbach and Crowley (2009), Shepardson and Britsch (2001) and Brenneman and Louro (2008) all found that elementary age students tended to record what they expected or wanted to see, rather than a realistic depiction of an object. The pre- and post-assessments and journal entries in this study contradict those previous findings. Accuracy scores on the pre-assessment were high and scores did not increase significantly from the pre-assessment to the post-assessment; journal entries were also surprisingly accurate. Where observations did display inaccuracies, for the most part they were based on the students' still developing drawing and writing skills, rather than on an intentional depiction of an inference or preconception.

Although it is difficult to view the data from the weekly journals through a quantitative lens, it is still important to evaluate what information these entries might add to the results of this study. Accuracy is at its highest during Week One, the week during which students were asked to record their observations only in writing. The average for Week One is higher, in fact, than even the class average for the post-assessment. The averages for Week Two, when students were asked to record only in drawing, and Week Four, when students were encouraged to both write and draw, have only a .05 difference. 
As Week Two and Four both had more drawing than writing (based in Week Four on student preference, which is discussed later in this section), it appears that students are more able to accurately record their observations using words rather than pictures. This may be affected by the students' still developing artistic abilities, as at seven- to nineyears-old, children are still developing fine motor skills and learning techniques for representing something in visual form.

The lowest score for Accuracy was Week Three. During Week Three, the weather was slightly cooler than in the other three weeks and there was a light mist. During the interviews, when asked what they did not like about being in the garden, many of the students mentioned that they did not enjoy being outside during poor weather. The weather clearly had a negative effect on the students, as their performance in all three categories and their persistent memory of the experience show.

\section{Detail}

Ford (2005) found that young students are unlikely to make detailed recordings, even when the student is an enthusiastic observer. The results of this study support those findings. Students could often be heard in the garden excitedly discussing the plants with their peers, and yet failing to make detailed recordings. However, the significant increase in the class scores from the pre-assessment to the post-assessment show that with instruction, support and practice students can increase their attention to detail and the quality of their recordings. This explicit instruction guided students in their progression from "novice" to "intermediate" (Eberbach and Crowley, 2009) status. 
Detail is highest in Weeks Two and Four, and again the lowest during Week Three. While students were more accurate when they recorded their observations in writing, they were able to capture more detail in drawings than in words. This may be reflective of students' developing abilities, as they are still slow, thoughtful writers with limited supplies of adjectives. However it may also reflect this study's removal from a truly discipline-specific context, as Eberbach and Crowley (2009) discuss. Students may have been better able to capture detail using drawings than writing because they are still developing a scientific vocabulary and were lacking the necessary words to describe what they were observing.

\section{Quantitative Data}

Eberbach and Crowley (2009) and Shepardson and Britsch (2001) both noted that students tended to neglect to record certain types of observations, in particular quantitative data. Class performance on the pre-assessment certainly supports that finding, as not a single student counted, measured, estimated or used any other form of quantitative data. Performance on the post-assessment as well as data from the students' journal entries clearly show a significant improvement in this area. After having received guidance on the importance of including this type of data as well as explicit instruction on how to do so, students were much more likely to include quantitative data in their recordings.

The weekly results of the inclusion of Quantitative Data are unsurprising. Results were substantially higher during Week One than Week Two. Although students were encouraged to include labels of their pictures, few did so during Week Two, thus 
rendering it much more challenging to include quantitative data. Week Three was, again, the students' poorest week. Students did substantially better on Week Four than on any of the other previous three weeks, and in fact the Week Four class average is higher than the post-assessment class average. During the indoor direct instruction and modeling portion of Week Four, students were specifically encouraged to include this type of data, and during the outside experience students were consistently reminded to do so.

\section{LIMITATIONS}

Although the findings from this study are exciting, there are limitations to the study that make it challenging to generalize the results. As previously noted, this study took place in an atypical school setting - a small school with a math and science focus and entrance to the school only through a lottery process. Results might look very different in a larger public school setting with an open admission policy. The low number of participants and the low diversity within those participants are another limitation.

As in any education research, the inherent complexity of the classroom poses somewhat of a threat to generalization. The researcher in this study was a student-teacher in the classroom in which the study was conducted, and therefore had substantial but still limited control over the implementation of the study. Had the researcher had full control over implementation of the study, as well as the ability to more completely manage other classroom activities, results might have differed.

\section{RECOMMENDATIONS}

Due to the limitations discussed aboveit is difficult to generalize the results to other populations. It is important, however, that we continue to learn more about how to 
build a strong foundation for students practicing science at young ages, therefore it would beneficial to continue this research. This study was conducted with second graders over a period of a month. Mabie and Baker (1996) suggested that participants in their study benefited from sustained participation in a garden program, and Klemmer et al (2005) found that fifth graders had higher gains in their study than did younger students. A longer iteration of this study may find much higher gains.

Several questions also arose during the implementation of this study that could lend themselves to further exploration. For example, the science journals were used as both a scientific tool and a literacy strategy, but many students expressed a strong preference for drawing rather than writing in their journals. Students were asked to use their journals in two specifically different ways during the first two weeks of this study, in order to encourage them to recognize the importance of both writing and drawing as part of making high-quality records. The first week focused on writing and the second on drawing. Following that first session, many students expressed that they had found it challenging, and upon receiving instructions to draw rather than write during the second session the overall mood of the classroom reflected more enthusiasm for the project. Interview results reflected this preference, as all but one of the interview participants revealed that they either preferred drawing to writing, or that they found it easier. Vicenzo replied, 'I've always been a big fan of drawing. In words there are details I can't even really talk about too much but in drawings I can get all the details out." Despite this preference for drawing, all the interview participants said that it was important to do both. Further research into this preference could improve teachers' ability to guide students in their science journal usage. 
Blair (2009) suggests that a possible future direction for garden research would be explore how long the purported benefits of garden experience last. That direction is very relevant for this study as well. As mentioned previously, students continued to use their science journals throughout the year without prompting, and two students shared that the experience had affected their science practice at home. I also witnessed many proclamations of joy from the children when they found at the end of the year that the science journals were theirs to take home and keep. These are important findings, as they show that this process had a lasting, meaningful effect for these children. Although this study focused on the short-term effects, it is important to know if this truly can have a long-term effect on students and their scientific habits.

Finally, although the skill of being a scientific observer is critical and foundational, it does not stand alone. The next logical step in the progression is to take these observations and begin to ask questions. The original intention in this study was to naturally progress toward an inquiry activity with the students, and to evaluate how their observations affected that process, in particular the asking of questions. It proved logistically impossible to incorporate that aspect into this particular piece of research, but it provides a clear direction in which to further this research in the future. 


\section{References}

Aschbacher, P., \& Alonzo, A. (2006). Examining the utility of elementary science notebooks for formative assessment purposes. Educational Assessment, 11(3\&4), 179-203.

Blair, D. (2009). The child in the garden: An evaluative review of the benefits of school gardening. The Journal of Environmental Education, 40(9), 15-38.

Brenneman, K., \& Louro, I. F. (2008). Science journals in the preschool classroom. Early Childhood Education Journal, 36(2), 113-119. doi: 10.1007/s10643-008-0258-z

Eberbach, C., \& Crowley, K. (2009). From everyday to scientific observation: How children learn to observe the biologist's world. Review of Educational Research, 79(1), 39-68. doi: 10.3102/0034654308325899

Ford, D. (2005). The challenges of observing geologically: Third graders' descriptions of rock and mineral properties. Science Education, 89, 276-295.

Garcia-Mila, M., \& Andersen, C. (2007). Developmental change in notetaking during scientific inquiry. International Journal of Science Education, 29, 1035-1058.

Gunel, M., Hand, B., \& Prain, V. (2007). Writing for learning in science: A secondary analysis of six studies. International Journal of Science and Mathematics Education, 5, 615-637.

Johnston, J. S. (2009). What does the skill of observation look like in young children?. International Journal of Science Education, 31(18), 2511-2525. doi: 10.1080/09500690802644637

Kellert, S. R. (2002). Experiencing nature: Affective, cognitive, and evaluative development in children. In P. H. Kahn Jr. \& S. R. Kellert (Eds.), Children and nature: Psychology, sociocultural and evolutionary investigations (pp. 117-151). Cambridge, MA: MIT Press.

Klemmer, C. D., Waliczek, T. M., \& Zajicek, J. M. (2005). Growing minds: The effect of a school gardening program on the science achievement of elementary students. HortTechnology, 15(3), 448 - 452.

Kuhn, D., Garica-Mila, M., \& Anderson, C. (1995). Strategies of knowledge acquisition. Society for Research in Child Development Monographs, 60, 1-128. 
Mabie, R., \& Baker, M. (1996). A comparison of experiential instructional strategies upon the science process skills of urban elementary students. Journal of Agricultural Education,37(2), 1-7.

McQuitty, V., Dotger, S., \& Khan, U. (2009, December).Writing science/science writing: A theoretical framework of the writing/science process in the elementary grades. Paper presented at The National Reading Conference/Literacy Research Association.

National Research Council. (2011). A Framework for K-12 Science Education: Practices, Crosscutting Concepts, and Core Ideas. Committee on a Conceptual Framework for New K-12 Science Education Standards. Board on Science Education, Division of Behavioral and Social Sciences and Education. Washington, DC: The National Academies Press.

Norris, S. P. (1984). Defining observational competence. Science Education, 68, 129142.

Pigg, A. E., Waliczek, T. M., \& Zajicek, J. M. (2006). Effects of a gardening program on the academic progress of third, fourth, and fifth math and science students. HortTechnology, 16(2), 262-264.

Ruiz-Primo, M. A., Li, M., Shavelson, R. J. (2002). Looking into students' science notebooks: What do teachers do with them? (CSE Technical Report 562). Los Angeles, CA: University of California, Center for the Study of Evaluation. (ED465806).

Schauble, L. (1990). Belief revision in children: The role of prior knowledge and strategies for generating knowledge. Journal of Experimental Psychology, 49, 3157.

Shepardson, D. P., \& Britsch, S. J. (2001). The role of children's journals in elementary school science activities. Journal of Research in Science Teaching, 38(1), 43-69. 


\section{Appendix A: Unit Outline}

\section{Week One}

Materials:

Science Journals

Jeweler's Loupes

Rulers

Lesson Plan: Lead class discussion about the importance of making high quality observations when doing science, and what that looks like. Introduce the criteria of accuracy, detail, and including quantitative data. Explain that in this lesson, we are going to focus on just using writing in our observations. Model the process using a leaf or plant brought in from the garden. Explain the parameters of working in the garden - stay in the bark chips area, choose a natural object, it is okay to work collaboratively but each student must do their own recordings in their own journals. Work in the garden with students for 45 minutes.

\section{Week Two}

Materials:

Science Journals

Colored pencils, crayons, markers

Jeweler's Loupes

\section{Rulers}

Lesson Plan: Lead class discussion on what went well last week and what needed more work. Using student examples, further refine the ideas of accuracy, detail and quantitative data. Explain that this week we are going to focus on drawing, although it is recommended to use some text in the form of labels. We will start by sketching the whole plant, then draw one small part of the plant (ie a petal, leaf, stamen), then finish by drawing a detailed drawing using their jeweler's loupes. Model the process inside the classroom. Work in the garden for 30 minutes, then work in the classroom for fifteen so that students can color their pictures or further refine. 
Week Three

Materials:

Science Journals

Colored pencils, crayons, markers

Jeweler's Loupes

Rulers

Lesson Plan: Lead class discussion on the value of including both written and drawn recordings and how some properties of objects are easier to represent in one or the other format. Using student examples, further refine the three criteria. Explain that this week we are going to use both writing and drawing. Emphasize the importance of including quantitative data - explain how some plants are categorized according to number of petals, leaves, reproductive parts or other characteristics. Model the process inside the classroom. Work in the garden for 30 minutes then work in the classroom for fifteen so that students can color their pictures or further refine.

\section{Week Four}

Materials:

Science Journals

Colored pencils, crayons, markers

Jeweler's Loupes

Rulers

Lesson Plan: Lead class discussion that incorporates all the material previously covered. Explain that this is the final week and an opportunity to show all that they have learned and that they can use both writing and drawing. Issue a challenge that a person should be able to find the plant they have observed based on their observations. Model the process inside the classroom. Work in the garden for 30 minutes then work in the classroom for fifteen so that students can color their pictures or further refine. 
Appendix B: Assessment Rubric

\begin{tabular}{|l|l|l|l|}
\hline CRITERIA & 1 & 2 & 3 \\
\hline Accuracy & $\begin{array}{l}\text { Observations are } \\
\text { mostly inaccurate. }\end{array}$ & $\begin{array}{l}\text { Observations have some } \\
\text { inaccuracies. }\end{array}$ & $\begin{array}{l}\text { Observations are } \\
\text { all or mostly } \\
\text { accurate. }\end{array}$ \\
\hline Detail & $\begin{array}{l}\text { Observations have } \\
\text { little to no detail. }\end{array}$ & $\begin{array}{l}\text { Observations include basic, } \\
\text { conspicuous details and/or } \\
\text { use plain descriptions. }\end{array}$ & $\begin{array}{l}\text { Observations } \\
\text { include } \\
\text { inconspicuous } \\
\text { details and/or use } \\
\text { rich descriptions. }\end{array}$ \\
\hline $\begin{array}{l}\text { Qualitative } \\
\text { Data }\end{array}$ & Does not include. & Estimates. & $\begin{array}{l}\text { Counts or } \\
\text { measures. }\end{array}$ \\
\hline
\end{tabular}




\section{Appendix C: Interview Questions}

Do you have a garden at home?

(If yes) Do you ever work in the garden at home? Can you tell me about that?

Before we started going out into the garden as a class to do observations, had you ever spent any time in the garden?

(If yes) Did a teacher ever take you out for a class like I did? Can you tell me about that?

Did you like going out into the garden to do observations?

What did you like about it?

Was there anything you didn't like about it?

Before we started using them, had you ever used a science journal before?

(If yes) Can you tell me about that?

Had anyone ever taught you how to make good scientific observations before?

(If yes) Who and when? Can you tell me more about that it?

Now that we've done this, what do you think makes a good scientific observation?

Do you think it's important to make good observations when you are doing science?

(If yes) Why?

How was it different doing observations inside versus out in the garden? Did you like one or the other more, or was one harder or easier?

Did you have a preference between writing and drawing when you were doing your observations? 